\title{
OS MEIOS E AS CONDIÇÕES DE VIDA DOS AGRICULTORES FAMILIARES PRODUTORES DE TABACO - UM ESTUDO NO MUNICÍPIO DE LARANJEIRAS DO SUL/PR ${ }^{1}$
}

\author{
Anderson Sartorelli ${ }^{2}$ \\ Anelise Graciele Rambo ${ }^{3}$
}

\section{Resumo}

Este estudo, ao trazer uma proposta teórico-metodológica, objetiva compreender como vivem os agricultores familiares produtores de tabaco no município de Laranjeiras do Sul/PR. Desta forma, a proposta desenvolvida consistiu no levantamento do Índice de Meios de Vida (IMV) e do Índice de Condições de Vida (ICV) tendo em vista a implementação da Convenção Quadro para o Controle do Tabaco (CQCT), um tratado internacional do qual o Brasil é país signatário e facilitador. Sendo assim, conhecer a maneira como os agricultores sobrevivem no meio rural, torna-se importante, sobretudo para orientar ações ou políticas de diversificação que contribuam para o desenvolvimento rural. A proposta metodológica está baseada na abordagem das capacitações de Amartya Sen e na perspectiva dos meios de vida de Frank Ellis. As hipóteses que embasaram esta pesquisa consideram que, por um lado, as condições de vida dos agricultores familiares produtores de tabaco são influenciadas pela diversificação de seus meios de vida e, por outro lado, que o tabaco contribui para ampliar o capital financeiro das famílias, o que não necessariamente se reverte em melhores condições de vida. Para chegar aos resultados da pesquisa, foram aplicados dois questionários a quarenta famílias produtoras de tabaco no município. O primeiro buscou levantar os meios de vida das famílias, o que

\footnotetext{
${ }^{1}$ Pesquisa de iniciação científica desenvolvida no âmbito do edital № 160/UFFS/2012 Pibic.

${ }^{2}$ Bacharel em Ciências Econômicas (UFFS). E-mail: anderson.sartorelli@hotmail.com

${ }^{3}$ Mestre em Geografia (UFRGS). Doutora em Desenvolvimento Rural (PGDR/UFRGS).

Professora da Universidade Federal da Fronteira Sul (UFFS). E-mail: ane_rambo@yahoo.com.br
} 
estas possuem para sobreviverem. O segundo questionário procurou levantar as condições de vida destas famílias, objetivando captar as percepções das mesmas acerca destas condições. Além disso, foi criada uma tipologia quanto ao grau de diversificação dos meios de vida. Desta forma, foi possível observar e analisar as condições de vida das famílias diversificadas, especializadas e pouco diversificadas do referido município. Com relação aos resultados, pode-se dizer que a hipótese foi confirmada, sendo que as famílias diversificadas possuem melhores meios e condições de vida em relação às demais. Enquanto que o IMV médio ficou em 0,655 , as famílias diversificadas apresentaram IMV de 0,660, seguidas das pouco diversificadas $(0,654)$ e das especializadas $(0,646)$ Já o ICV médio alcançou 0,738 . Neste caso, as famílias diversificadas e pouco diversificadas demonstraram ICV de 0,742 e as especializadas 0,734 .

Palavras-Chave: agricultura familiar; condições de vida; desenvolvimento rural; diversificação; meios de vida.

\section{FAMILY FARMERS TOBACCO GROWERS LIVELIHOODS AND LIVE CONDITIONS OF- A STUDY IN LARANJEIRAS DO SUL (PR)}

\section{Abstract}

This study, to bring a theoretical-methodological proposal, aims to understand how living family farmers growers tobacco in Laranjeiras do Sul/PR. Thus, the proposal developed the Livelihoods Index (IMV) and Living Condition Index (ICV) regarding the implementation of the Framework Convention on Tobacco Control (FCTC), an international treaty to which the Brazil is a signatory and facilitator. Thus, to know how family farmers survive in rural areas, it becomes especially important for diversification actions or public policies that contribute to rural development. The methodology is based on the capabilities approach of Amartya Sen and the livelihoods perspective of Frank Ellis. The assumptions that supported this research consider that, on the one hand, the life conditions of family farmers producing tobacco are influenced by diversifying their livelihoods and, moreover, that tobacco contributes to increase financial capital of families, which does not necessarily proceeds in better living. To get the results of the survey, two questionnaires were applied to forty families. The first questionnaire was to identify the livelihoods of families, which they have to survive. The second questionnaire was to identify the living 
conditions of these families, aiming to grasp the perceptions about its conditions. In addition, we created a typology of livelihoods diversification degree. Thus, it was possible to observe and analyze the living conditions of diversified, specialized and less diverse families. Regarding the results, it is possible to consider that hypothesis was confirmed, and the diversified families have better means and living conditions in relation to others. While IMV average stood at 0,655 , the diversified families had IMV of 0,660 , succeed by less diversified (0.654) and specialized (0.646) Already ICV average reached 0.738 . In this case, diversified and less diversified families showed 0,742 ICV and specialized families pointed 0,734.

key words: family farmig; living conditions; rural development; diversification, livelihoods.

\section{INTRODUÇÃO}

De acordo com o Departamento de Estudos Socioeconômicos Rurais (DESER, 2010), o Brasil é o maior exportador de tabaco do mundo. Grande parte dessa produção é oriunda da agricultura familiar. Segundo dados da Associação dos Fumicultores do Brasil (Afubra) ${ }^{4}$, em 2012 foram aproximadamente 165.170 famílias produtoras de tabaco no país, as quais se valem do uso intensivo de mão de obra, baixo nível de mecanização, em sistemas de integração com as empresas de tabaco, que negociam os preços a serem pagos no final de cada safra, com a associação de representação dos produtores (INCA, 2012).

$\mathrm{Na}$ perspectiva de Zotti (2010), o cultivo do tabaco é bastante controverso, pois de um lado tem-se a grande importância econômica dessa atividade, tanto para os agricultores familiares, que estão na base do processo, quanto para os atravessadores, as indústrias, e os empregos nelas gerados, bem como para o Estado, através dos impostos recolhidos desde a produção até a comercialização do produto final. Entretanto, por outro lado, o tabaco apresenta sérios problemas ao bem estar das pessoas, afetando

\footnotetext{
${ }^{4}$ A Associação dos Fumicultores do Brasil (AFUBRA) foi fundada em 21 de março de 1955, no município de Santa Cruz do Sul/RS e atua nos estados do Rio Grande do Sul, Santa Catarina e Paraná. A entidade representa os interesses da classe dos fumicultores, pequenos agricultores que têm no cultivo do tabaco a principal fonte de renda para manutenção e viabilidade da propriedade rural (AFUBRA, 2013).
} 
desde os agricultores que se dedicam à atividade, até os consumidores ativos e passivos, ocasionando sérios riscos à saúde humana (INCA, 2012).

Com relação a esse cenário envolvendo o cultivo do tabaco, Schneider (2010a) corrobora enfatizando que as condições de produção do tabaco expõem os agricultores familiares a situações paradoxais. De um lado, praticam uma atividade altamente rentável e lucrativa, que apesar de demandar uso intenso de mão de obra, pode ser realizada em pequenas áreas de terra, dado o volume total produzido por área plantada. Por esta razão, a maximização do fator trabalho representa uma vantagem comparativa frente aos demais sistemas de cultivo ou criações, gerando e/ou conferindo competitividade incomum aos estabelecimentos de pequeno porte voltados à produção do tabaco. Por outro lado, esta produção gera uma situação de dependência e de vulnerabilidade, que fragilizam estas famílias e geram situações de pobreza e risco.

No entendimento de Schneider (2010a), a dependência decorre do fato de que a produção intensiva de tabaco demanda elevada mobilização de recursos (insumos, sementes, adubos e defensivos), os quais são fornecidos pelas empresas que compram o tabaco por meio da produção integrada. Uma vez integrado, o agricultor fica comprometido a entregar à empresa a produção mediante contratos. Outra vulnerabilidade decorre da exposição da saúde humana a situações de risco pela produção do tabaco ser intensiva no uso de agroquímicos e pelas plantas concentrarem altas taxas de nicotina que, quando manejados de forma intensiva, podem ser nocivas à saúde humana.

O cultivo do tabaco, na visão de Zotti (2010), torna-se uma "faca de dois gumes", em que, por um lado é economicamente importante para o país, para o Estado e para os fumicultores ao mesmo tempo em que, por outro, confere sérios problemas ambientais e de saúde tanto para quem planta, quanto para quem o consome. Para Zotti (2010), é com essa "faca de dois gumes" que os agricultores familiares produtores de tabaco convivem diariamente, em suas diferentes realidades. Alguns agricultores sentem prazer em cultivar tabaco, pois delegam a ele algumas importantes conquistas que obtiveram e grandes oportunidades de melhorar suas condições de vida. Outros, porém com tristeza por não encontrar outra maneira de se manter viáveis no campo, continuam sentindo-se obrigados a cultivá-lo. Entre outras, essas duas distintas realidades descritas podem ser observadas no município de Laranjeiras do Sul/PR.

Outro elemento que deve ser levado em consideração é a implementação, em 2005, da Convenção Quadro para o Controle do 
Tabaco (CQCT), um tratado internacional no âmbito da Organização Mundial da Saúde (OMS) que prevê que os países signatários passem a adotar medidas multisetoriais para reduzir a demanda e oferta de produtos do tabaco (SCHNEIDER, 2010a). A implementação desta Convenção, sem dúvida é de extrema relevância no combate ao tabagismo em todo o mundo, entretanto, suas ações podem penalizar os agricultores que dependem da renda gerada pelo tabaco para sobreviverem. Esses dois lados são levados em consideração pelos grupos de trabalho, que subsidiam a CQCT, mas também se preocupam em avaliar alternativas viáveis aos agricultores familiares para substituição das áreas cultivadas com tabaco.

Portanto, a temática da produção de tabaco se torna relevante e merece uma atenção maior por parte de pesquisadores, para que soluções mais adequadas sejam encontradas, aliviando os impactos sobre os integrantes desse mercado, sejam os próprios consumidores, ativos e passivos e, sobretudo os atores da cadeia produtiva do tabaco, incluindo os produtores que muitas vezes ficam à margem do processo de discussão, no qual, são alguns dos principais envolvidos e interessados. Desta forma, conhecer como os produtores de tabaco estão organizados e a maneira como sobrevivem no meio rural pode ser importante inclusive para orientar políticas ou ações voltadas para o desenvolvimento rural.

Sendo assim, o objetivo deste estudo consistiu em investigar os meios de vida dos agricultores familiares produtores de tabaco do município de Laranjeiras do Sul/PR, bem como as condições de vida destes agricultores, por meio da aplicação de questionários que resultaram no Índice de Meios de Vida (IMV) e no Índice de Condições de Vida (ICV).

Frente a este objetivo, são levantadas duas hipóteses, quais sejam, (a) a produção de tabaco contribui, sobretudo para ampliar o capital financeiro das famílias produtoras de tabaco, o que não necessariamente se reverte em melhores condições de vida; (b) as condições de vida dos agricultores familiares produtores de tabaco são influenciadas pela diversificação de seus meios de vida, o que, por sua vez, amplia sua liberdade em optar por diferentes estilos de vida.

Para tal, utilizou-se a abordagem das capacitações de Amartya Sen que pode ser entendida como uma teoria que considera as oportunidades reais e da igualdade de participação das pessoas na escolha dos princípios de justiça voltados para a organização da 
sociedade (MARIN, 2005). Também utilizou-se a abordagem dos meios de vida de Frank Ellis, que se refere a uma ferramenta analítica que vem sendo utilizada com maior ênfase nos estudos sobre a pobreza rural no mundo, pois apresenta certa efetividade em explicar como as pessoas fazem para sobreviver em situações de riscos e/ou crises ambientais, sociais ou econômicas (PERONDI, 2007) ${ }^{5}$.

Dessa forma, buscou-se conhecer como vivem os agricultores familiares produtores de tabaco no município de Laranjeiras do Sul. Para alcançar este objetivo, propôs-se uma metodologia de compreensão dos meios e das condições de vida das famílias produtoras de tabaco. Levou-se em consideração o que as famílias possuem para viver, ou seja, seus capitais, que caracterizam seus meios de vida, e a percepção das famílias em relação aos efeitos destes capitais, o que caracteriza as condições de vida. Desta forma, procurou-se estudar os capitais e os efeitos destes na vida das famílias produtoras de tabaco de Laranjeiras do Sul/PR.

Sendo assim, este artigo encontra-se estruturado em cinco partes, além desta introdução. Na segunda seção trata-se da Convenção Quadro para o Controle do tabaco, abordando seus principias aspectos e objetivos. Na terceira parte é abordado o referencial teórico do artigo, com as contribuições de Amartya Sen e sua abordagem das capacitações e a ideia do desenvolvimento como liberdade, e também a abordagem de Frank Ellis referente aos meios de vida. Na quarta seção, aborda-se a metodologia utilizada no estudo empírico. Na quinta parte são apresentados os resultados e as análises da pesquisa em Laranjeiras do Sul/PR e por fim, constam as considerações finais e referências bibliográficas.

\footnotetext{
${ }^{5}$ Importa ressaltar que o trabalho dá continuidade a um estudo piloto realizado por pesquisadores do Programa de Pós-Graduação em Desenvolvimento Rural da Universidade Federal do Rio Grande do Sul (PGDR/UFRGS) no município de Arroio do Tigre (RS) no ano de 2012, a pedido da Secretaria da Agricultura Familiar do Ministério do Desenvolvimento Agrário (SAF/MDA), tendo em vista que o Brasil é país signatário e facilitador da Convenção Quadro para o Controle do Tabaco (CQCT). O objetivo deste estudo piloto consistiu em elaborar uma metodologia que pudesse auxiliar na compreensão dos meios de vida dos agricultores familiares produtores de tabaco, orientando assim, as políticas de diversificação em áreas de tabaco, no âmbito dos países signatários da CQCT. Assim sendo, mostrou-se necessário um instrumento de pesquisa de rápida e fácil aplicação.
}

136 


\section{CONVENÇÃO QUADRO PARA O CONTROLE DO TABACO (CQCT)}

Nas últimas décadas tem se intensificado a luta contra o tabagismo à nível nacional e mundial. Contudo, o tabaco tem resistido a leis e campanhas que o combatem. O Instituto Nacional do Câncer (INCA) estima que mais de 30 milhões de brasileiros fumem, e que em todo mundo esse número chega a 1,3 bilhão. $O$ Sindicato Interestadual da Indústria do Tabaco (Sinditabaco) aponta que são consumidos anualmente cerca de 140 bilhões de cigarros no Brasil. A Organização Mundial de Saúde (OMS) considera que o tabagismo é a principal causa de morte evitável em todo o mundo (SOUZA, 2009).

Reconhecendo a expansão do consumo do tabaco como um problema global, em 1996, a 49a Assembleia Mundial da Saúde (órgão diretor supremo da OMS, composta pelos representantes de 190 países membros) adotou uma resolução buscando junto ao diretor geral, uma iniciativa no sentido de elaborar uma Convenção Quadro para controlar a expansão do tabaco. Esta Convenção Internacional foi a primeira adotada na história da OMS e tem como objetivo central o controle da expansão global do consumo de tabaco e de suas consequências para o ser humano (SCHNEIDER, 2010a). Dessa forma, em concordância com o amplo reconhecimento dos graves danos sanitários, sociais e econômicos decorrentes do tabagismo teve início a discussão da chamada Convenção Quadro para o Controle do Tabaco (CQCT), assinada pelo Brasil em 2005 e ratificada no final do mesmo ano. A CQCT é o primeiro tratado internacional de saúde pública, negociado por mais de 190 países durante apenas quatro anos (1999 - 2003), sob orientação da OMS (SOUZA, 2009).

De acordo com Souza (2009), a Convenção Quadro determina padrões internacionais para o controle do tabaco, prevendo a adoção de ações relacionadas à propaganda e patrocínio, política de impostos e preços, rotulagem, ao comércio ilícito e ao tabagismo passivo, a dependência da nicotina, além de cooperação nas áreas cientifica, educacional e sanitária, dentre outras. $\dot{E}$ portanto, composta por medidas intersetoriais e abrangentes, e tem como objetivo principal à preservação das gerações presentes e futuras das consequências sanitárias, sociais, ambientais e econômicas do consumo e da exposição à fumaça do tabaco. Contudo, os impactos a médio e longo prazos da entrada em 
vigor da Convenção Quadro poderão implicar em importantes mudanças, tanto nos hábitos dos fumantes quanto na cadeia produtiva do tabaco no Brasil e no mundo (SOUZA, 2009).

Conforme descreve Schneider (2010a), a preocupação com as condições de produção dos agricultores que cultivam tabaco e os efeitos danosos do tabagismo sobre os consumidores, trouxe um ponto de consenso a favor de sua restrição. Este posicionamento foi reforçado a partir do momento em que cientistas da área de saúde passaram a demonstrar e comprovar não apenas os malefícios do tabaco aos seus consumidores diretos (os fumantes), mas também àqueles denominados de usuários passivos, entre os quais os indivíduos que comungam ambientes com fumantes e os próprios produtores de tabaco. $\mathrm{Na}$ medida em que pesquisas científicas passaram a demonstrar os efeitos causais negativos do uso contínuo do tabaco sobre a saúde humana, bem como a influência da dinâmica do livre comércio na expansão da epidemia do tabagismo, passaram a ser criados mecanismos de controle ao consumo e a produção. Como já citado, foi este cenário que levou à implementação da CQCT, a qual prevê que os países que dela fazem parte passem a adotar medidas para reduzir a demanda e oferta de produtos do tabaco (SCHNEIDER, 2010a).

De acordo com Schneider (2010a) uma das principais metas da Convenção consiste em diminuir as cinco milhões de mortes anuais decorrentes do uso do tabaco que, segundo estimativas, tendem a aumentar em $100 \%$ nos próximos 10 ou 20 anos, caso as tendências de expansão do consumo de tabaco sejam mantidas de acordo com a OMS. A CQCT, de acordo com Zotti (2010), conta atualmente com a participação de 190 países membros da OMS, e prevê em nível mundial a união de esforços para a adoção de um conjunto de medidas a fim de deter a expansão global do consumo de tabaco e por consequência, suas implicações negativas sobre a saúde das pessoas.

De acordo com texto oficial da CQCT, o artigo terceiro do mesmo relata que:

O objetivo da presente Convenção e de seus protocolos é proteger as gerações presentes e futuras das devastadoras consequências sanitárias, sociais, ambientais e econômicas geradas pelo consumo e pela exposição à fumaça do tabaco, proporcionando uma referência para as medidas de controle do tabaco, a serem implementadas pelos 
governos nos níveis nacional, regional e internacional, a fim de reduzir de maneira contínua e substancial a prevalência do consumo e a exposição à fumaça do tabaco (FCTC, 2003, p.5. Tradução livre).

As medidas adotadas pela Convenção têm como base alguns princípios norteadores expressos no seu artigo 4ำ, que são: o direito das pessoas à informação sobre a gravidade dos riscos decorrentes do consumo de tabaco; o direito de acesso aos mecanismos de prevenção e de apoio para cessação de fumar; além da proteção de toda pessoa contra a exposição involuntária à fumaça do tabaco (BRASIL, 2011).

No que tange à questão da produção de tabaco, a Convenção Quadro sugere ações a serem realizadas pelos países signatários para uma futura redução na demanda do produto. Entretanto, o cumprimento dessas metas ocasionará uma possível instabilidade econômica no médio e longo prazo para aqueles agricultores que dependem principalmente da renda gerada pelo cultivo do tabaco para sobreviverem (SOUZA, 2009). Buscando prevenir as consequências de uma possível redução de produção e renda dos produtores de tabaco, a própria CQCT assume compromissos de incentivo e proteção à reconversão dos produtores de tabaco, expressos pelos artigos 17 e 18 da referida Convenção.

Conforme o texto oficial, o artigo 17 trata do apoio a atividades alternativas economicamente viáveis à cultura do tabaco. $O$ referido artigo prevê que:

As partes em cooperação entre si e com as organizações intergovernamentais internacionais e regionais competentes promoverão, conforme proceda, alternativas economicamente viáveis para os trabalhadores, os cultivadores e, eventualmente, os varejistas de pequeno porte (BRASIL, 2011, p. 44).

Já o artigo 18 trata da proteção ao meio ambiente e à saúde das pessoas, neste sentido: 
Em cumprimento às obrigações estabelecidas na presente Convenção, as Partes concordam em prestar devida atenção, no que diz respeito ao cultivo do tabaco e à fabricação de produtos de tabaco em seus respectivos territórios, à proteção do meio ambiente e à saúde das pessoas em relação ao meio ambiente (BRASIL, 2011, p. 44).

O Brasil ratificou sua participação na Convenção Quadro em 2005 e assumiu o compromisso de implementar as ações previstas em relação à regulação do consumo e na apresentação de alternativas economicamente viáveis a produção de tabaco (SCHNEIDER, 2010a). Com a ratificação da CQCT, o Governo Federal também assumiu no mesmo ano o compromisso de implementar o Programa Nacional de Diversificação em Áreas Cultivadas com Tabaco (BRASIL, 2011).

Segundo o Deser (2006), durante a primeira Conferência das Partes $\left(\mathrm{COP}^{6} 1\right)$ - encontro dos países que ratificaram a CQCT ocorrida em 2006, o Brasil liderou as negociações juntamente com outros países produtores e propuseram a criação de um grupo de estudo $(A d h o c)^{7}$ para discutir alternativas ao cultivo do tabaco, que em linhas gerais, tem como objetivos: a) avaliar o status das alternativas economicamente viáveis existentes para a produção de tabaco; b) recomendar mecanismos para avaliar o impacto da Convenção Quadro sobre os trabalhadores da indústria, agricultores e, em caso pertinente, varejistas de pequeno porte; c) avaliar políticas efetivas para apoiar o processo de transição, levando em consideração as pesquisas sobre diversificação; d) recomendar iniciativas rentáveis de diversificação (SOUZA, 2009).

Por estes compromissos assumidos, o Brasil ganhou importante papel como liderança internacional no debate para a implementação da Convenção Quadro e seus desdobramentos. Este reconhecimento do país no cenário internacional foi confirmado através da realização da primeira reunião do Grupo de Estudos $A d$

${ }^{6}$ COP é o órgão executivo da Convenção e é formada pelos países que a ratificaram, aceitaram ou aprovaram. O principal papel da COP é tomar decisões necessárias para a efetiva implementação da Convenção, promovendo, facilitando e monitorando todo o processo executado pelos Estados Partes (BRASIL, 2011).

O Grupo de estudos $A d$ hoc foi criado na primeira Conferência da Partes (COP 1), ocorrida em Genebra em fevereiro de 2006. As partes consideradas são os países signatários da Convenção Quadro.

140 
Hoc, ocorrida em fevereiro de 2007, que se tornou a instância de discussão e elaboração de propostas aos cultivos alternativos ao tabaco (SCHNEIDER, 2010a).

De acordo com Schneider (2010a), na segunda Conferência das Partes (COP 2, ocorrida em Bankok em julho de 2007) os países signatários da Convenção Quadro decidiram manter as atividades do Grupo de Estudos Ad Hoc e solicitaram a apresentação de estudos e pesquisas que pudessem oferecer perspectivas viáveis e sustentáveis de diversificação à produção de tabaco. Foi esse o motivo que levou a realização da segunda reunião oficial do Grupo de Trabalho Ad Hoc, em 2008 na cidade do México. Esta reunião destacou que para implementar alternativas bem sucedidas e economicamente sustentáveis para o cultivo do tabaco, seria necessário abordar não somente a renda do agricultor e a rentabilidade das culturas, mas entender também todos os aspectos relacionados aos seus meios de vida. A abordagem dos meios de vida foi identificada como mais apropriada para orientar a implementação dos artigos 17 e 18 da Convenção Quadro para o Controle do Tabaco da OMS (SCHNEIDER, 2010b).

Como já citado neste trabalho, a CQCT congrega um conjunto de medidas multissetoriais para reduzir a demanda por produtos de tabaco e as doenças e mortes relacionadas ao mesmo. Por outro lado, a Comissão Nacional para Implementação da Convenção Quadro para Controle do Tabaco - CONICQ (2012) alerta para a necessidade de ações e medidas para resguardar os meios de vida dos agricultores de possíveis impactos econômicos que a redução na procura pelo tabaco possa ocasionar na sua renda. Sendo assim, a seguir são apresentadas as abordagens teóricas que deverão auxiliar na compreensão de como vivem os agricultores familiares produtores de tabaco para, a partir disso, ser possível elaborar políticas mais adequadas a estas realidades.

\footnotetext{
${ }^{8}$ A CONICQ foi criada em 1999 com o objetivo de subsidiar o Presidente da República nos posicionamentos e decisões do Brasil durante as rodadas de negociação da Convenção Quadro que ocorreram em 1999 e 2003. Também é responsável por articular a implementação da agenda governamental para cumprimento dos artigos do tratado. É presidida pelo Ministério da Saúde e composta por representantes de 18 ministérios (CONICQ, 2013).
} 


\section{ABORDAGEM DAS CAPACITAÇÕES E DOS MEIOS DE VIDA PARA ANALISAR A AGRICULTURA FAMILIAR PRODUTORA DE TABACO}

Nesta seção aborda-se o referencial teórico e os conceitoschave que deram sustentabilidade ao estudo. Estes se referem à abordagem das capacitações desenvolvida pelo economista Amartya Sen, o qual trabalha a ideia de desenvolvimento como liberdade, destacando que há uma confusão entre meios e fins do desenvolvimento. De modo a operacionalizar as ideias de Sen no contexto rural, da agricultura familiar e produção de tabaco será utilizada a abordagem dos meios de vida (livelihoods) do economista Frank Ellis ${ }^{9}$, tal como sugere o grupo de estudos ad hoc. Esta, diz respeito às opções e estratégias de trabalho, renda e produção das famílias rurais com o objetivo de diminuir sua vulnerabilidade em relação a crises, choques, instabilidade de mercado. $\mathrm{O}$ autor defende a importância da diversificação dos meios de vida. Defende-se aqui que esta diversificação possibilita a ampliação das liberdades.

\subsection{Os meios e fins do desenvolvimento e a abordagem das capacitações de Amartya Sen}

A ideia de desenvolvimento como liberdade foi desenvolvida pelo economista Amartya Kumar Sen. Sen nasceu na Índia em 1933, estudou na escola Visva-Bharati, Lecionou na Delhi School of Economics e na London School of Economics, de 1971 a 1982. Foi professor de filosofia e economia em Harvard por mais de uma década. Recebeu seu Ph.D. em 1959 no Trinity College (Cambridge University) com a tese sobre as escolhas de técnicas nas economias em desenvolvimento. Pode ser considerado o principal autor no mundo em teoria da escolha social e Economia do Bem-Estar (SEN, 2012). Este autor trabalha a ideia de desenvolvimento como liberdade, destacando que há uma confusão entre meios e fins do desenvolvimento. Normalmente os meios são considerados fins, ou seja, para Sen (2010. p. 28) "A utilidade da riqueza está nas coisas que ela nos permite fazer - as liberdades substantivas que ela nos ajuda a obter e não nela mesma".

Sen (2010) compreende o desenvolvimento enquanto expansão das liberdades e assim propõe uma distinção entre os

\footnotetext{
${ }^{9}$ Frank Ellis é bacharel em Economia Agrícola pela University of Reading, mestre em Economia pela London School of Economics e doutor em Economia University of Sussex.

142
} 
meios e os fins do desenvolvimento. Afirma que estes meios e fins devem ser estudados e analisados minunciosamente para uma compreensão mais plena do processo de desenvolvimento. Para o autor, o desenvolvimento tem de estar relacionado, sobretudo com a melhoria da vida e com a expansão das liberdades que as pessoas desfrutam. Expandir as liberdades que se tem razão para valorizar, não só torna a vida das pessoas mais rica e mais desimpedida, como permite que sejam seres sociais mais completos, ou seja, que interajam com o mundo em que vivem e influenciem esse mundo.

Com base na proposta apresentada por Sen (2010) as liberdades não são apenas os fins primordiais do desenvolvimento, mas também os meios principais. É preciso entender a relação empírica que vincula as diferentes liberdades. A eficácia da liberdade como instrumento reside no fato de que diferentes tipos de liberdades apresentam inter-relação entre si, e um tipo de liberdade pode contribuir para promover liberdades de outros tipos. Neste contexto, as liberdades políticas (sob a forma de livre expressão e eleições) contribuem para promover a segurança econômica. As oportunidades sociais (sob a forma de serviços de educação e de saúde) facilitam a participação econômica. Facilidades econômicas (sob a forma de oportunidade de participar no comércio e na produção) podem ajudar a gerar tanto riqueza pessoal como riqueza pública destinada para os serviços sociais. Portanto, liberdades de diferentes tipos podem fortalecer umas às outras (SEN, 2010). Na análise de Sen, o papel das liberdades dos indivíduos aparece fortemente fundamentado como a grande chave para uma sociedade alcançar o seu desenvolvimento pleno. Ou seja, o direito das pessoas em escolher o tipo de vida que desejam levar e a não privação das oportunidades que lhes aparecem pode ser considerado como a chave da análise seniana.

A identificação das diferentes formas de privação de liberdade permite diferenciar que a liberdade é limitada às vezes por processos inadequados, como a violação de direitos políticos e civis, $\mathrm{e}$ as vezes por oportunidades inadequadas, como um sistema de educação precário ou a fome involuntária (SANTOS, 2007). Segundo a mesma autora, mencionando Sen (2000), os processos inadequados estão relacionados à privação de liberdades formais, aquelas determinadas por lei, enquanto oportunidades inadequadas associam-se à negação de liberdades substantivas. Tanto processos quanto oportunidades têm sua importância na abordagem da pobreza como insuficiência de capacitações. 
De modo a explicitar as ideias mais gerais acima apresentadas, Sen desenvolve a abordagem das capacitações, explicando-a por meio de conceitos como intitulamentos e funcionamentos, os quais levariam a capacidade para funcionar.

Para Sen, os intitulamentos se referem ao que as pessoas têm ou possuem para viver. Os funcionamentos podem ser entendidos como as coisas que a pessoa tem razão de ser ou fazer, e as capacitações podem ser referidas ao conjunto desses funcionamentos, dentre os quais a pessoa pode escolher. Ou seja, seria como uma espécie de conjunto orçamentário na teoria do consumidor abordada pela microeconomia, mas que representa os diferentes tipos de vida que a pessoa pode levar (MARIN, 2005).

Em seu livro sobre o Desenvolvimento como Liberdade, Sen (2010), enfatiza que a expansão da liberdade é vista como o principal fim e o principal meio do desenvolvimento. Para o autor, o desenvolvimento consiste na eliminação de privações de liberdade que limitam as escolhas e as oportunidades das pessoas de exercer ponderadamente sua condição de agente. Ou seja, na abordagem de Sen a liberdade seria o principal fato motivador para se alcançar o desenvolvimento. Portanto, o desenvolvimento requer que se removam essas privações de liberdade, que na sua visão seriam: pobreza e tirania, carência de oportunidades econômicas e destituição social sistemática, negligência dos serviços públicos e intolerância ou interferência excessiva de Estados repressivos (SEN, 2010).

Em termos teóricos, a proposta de Sen baseia-se em um deslocamento de percepções acerca do desenvolvimento da sociedade, pois a centralidade da ação humana e da intervenção sobre a natureza deixa de ser baseada nos recursos (naturais, físicos ou criados pela ação humana) e nos atributos e passa a se fixar nas pessoas e nos meios que estas possuem. Segundo esta perspectiva, mais importante do que ter máquinas, equipamentos, acesso a tecnologias e dinheiro é a liberdade das pessoas poderem optar por fazer as coisas do modo que quiserem para alcançar os bens e recursos que desejam (SCHNEIDER, 2010b).

De acordo com Sen (2010), o enfoque nas liberdades humanas se contrapõe a visões mais restritas de desenvolvimento, como as que consideram desenvolvimento apenas a partir do crescimento do Produto Interno Bruto (PIB), aumento de rendas pessoais, industrialização, avanço tecnológico ou modernização social. Esses elementos, na visão de Sen, podem ser muito importantes como um meio de expandir as liberdades desfrutadas pelos membros da sociedade. Entretanto, as liberdades e/ou 0 
desenvolvimento dependem também de outros fatores, como as disposições sociais e econômicas (por exemplo, os serviços de educação e saúde) e os direitos civis (por exemplo, a liberdade de participar de discussões na sociedade).

A abordagem das capacitações de Sen, pode ser entendida como uma teoria que se refere à consideração das oportunidades reais e da igualdade de participação das pessoas na escolha dos princípios de justiça voltados para a organização da sociedade. Esta abordagem tende a ser vista como uma ampla estrutura normativa que pode ser usada para a avaliação do bem-estar individual e das organizações sociais, para o desenho de políticas e para propostas sobre mudanças na sociedade (MARIN, 2005).

De acordo com esta perspectiva, o bem-estar poderia ser avaliado de acordo com as capacitações que as diferentes pessoas possuem de promover os vários funcionamentos que Ihes tenham valor. Por exemplo, a diminuição da pobreza ou o desenvolvimento ocorreria quando as pessoas fossem capazes de expandir suas capacitações, não apenas seus funcionamentos efetivamente alcançados (MARIN, 2005).

Segundo Sen (2010) e a sua perspectiva, o bem-estar de uma pessoa pode ser entendido em termos de sua qualidade de vida, e o viver pode ser visto como um conjunto de funcionamentos inter-relacionados. A realização de uma pessoa, nesse sentido pode ser vista como o vetor de seus funcionamentos, tal noção de funcionamento está relacionada com a capacidade para funcionar, ou seja, a liberdade da pessoa em levar o tipo de vida que ela deseja. Os conceitos acima apresentados remetem ao que o autor denomina de meios e fins do desenvolvimento.

Distinguindo meios e fins, Sen (2001) operacionaliza sua proposta com base nos conceitos de entitlements (intitulamentos) e functionings (funcionamentos). Os intitulamentos representam 0 conjunto de combinações de bens ou mercadorias que cada pessoa pode ou está apta a possuir. Os alimentos, por exemplo, seriam os mais básicos. Os intitulamentos representam, portanto, os meios para atingir determinados fins, as condições para a realização de escolhas, sendo estabelecidos por ordenamentos legais, políticos e econômicos (KAGEYAMA, 2008; WAQUIL, et.al., 2007 apud Schneider, 2012).

Os funcionamentos por sua vez, como já mencionados sucintamente na seção anterior, remetem às realizações dos indivíduos, às reais oportunidades de escolha acerca de possíveis 
estilos de vida. Apesar de serem aspectos importantes da existência humana, a opulência e a utilidade não representam adequadamente o bem-estar e as condições de vida. Ou seja, o indivíduo necessita ter a capacidade de realizar um funcionamento (capability to function) e esta capacidade representa a combinação destes funcionamentos que os indivíduos podem realizar, refletindo a liberdade da pessoa para levar determinado tipo de vida ou outro (SEN, 2001; KAGEYAMA, 2008 apud Schneider, 2012). Desta forma, segundo Rambo et.al., (2013), entender o desenvolvimento requer mais que uma análise das condições de renda dos indivíduos. Requer uma abordagem integral, que observe os funcionamentos $e$ as capacitações das pessoas e como estas conseguem melhorar suas condições de vida.

Partindo da distinção entre intitulamentos e funcionamentos, temos agora um novo elemento para melhor compreendermos a abordagem Seniana sobre desenvolvimento como liberdade. Este remete à ideia de capacidades (capability). Para Sen (2010, p. 105) "a capacidade de uma pessoa consiste nas combinações alternativas de funcionamentos cuja realização é factível para ela". Portanto, a capacidade é um tipo de liberdade, chamada pelo autor de substantiva, de realizar combinações alternativas de funcionamentos, isto é, a liberdade para ter estilos de vida diversos (SEN, 2010).

A capacidade na teoria Seniana envolve, segundo Costa (2005) as condições externas para a realização dos funcionamentos. "O conjunto de capacidades representa a liberdade pessoal de realizar várias combinações para a escolha [...] a capacidade está associada às possibilidades de escolha e à liberdade do agente social" (COSTA, 2005. p. 6).

De acordo com Costa (2005), a análise e a noção dos intitulamentos torna o pesquisador social capaz se estabelecer relações entre situações estruturais que podem incentivar a expansão das capacitações ou, a partir da falta de determinados acessos a bens e serviços, reter capacitações, ocasionando um impedimento das pessoas a determinadas oportunidades.

\subsection{Abordagens da diversificação dos meios de vida de Frank Ellis}

Para implementar a proposta de Amartya Sen, utiliza-se, neste estudo a abordagem dos meios de vida (livehoods) de Frank Ellis. Esta é assumida enquanto uma ferramenta analítica, a qual vem sendo utilizada com maior ênfase nos estudos sobre a pobreza rural no mundo, porque apresenta uma grande efetividade em 
explicar como as pessoas fazem para sobreviver em situações de riscos e/ou crises ambientais, sociais ou econômicas (PERONDI, 2007). Neste estudo, a situação de risco remete, entre outros ao cenário que pode decorrer da implementação da Convenção Quadro para com os agricultores familiares produtores de tabaco.

Também vale a pena mencionar que o município de Laranjeiras do Sul, foco deste estudo, está situado em um território da Cidadania - o Território Cantuquiriguaçu - o que já indica uma situação de vulnerabilidade social e econômica ${ }^{10}$. Este território é considerado uma região pouco desenvolvida, como demonstra o Índice de Desenvolvimento Humano ${ }^{11}$ (IDH-M), que em 2010 estava situado em 0,659. Já o IDH do estado do Paraná e do Brasil no mesmo período correspondiam a 0,749 e 0,727 respectivamente (PNUD, 2013). O número de pessoas em extrema pobreza, segundo o Sistema de Informações Territoriais (SIT) é de aproximadamente 26.887 pessoas, o que corresponde a $11,5 \%$ da população do território Cantuquiriguaçu. Deste total de pessoas pobres, 19.217 ou $71,4 \%$ residem no campo (SIT, 2013), o que demonstra ainda mais o baixo nível de desenvolvimento rural da região.

A abordagem dos meios de vida foi desenvolvida inicialmente pelo cientista social Antonio Candido de Mello e Souza em sua obra intitulada como "os parceiros do Rio Bonito: estudo sobre o caipira brasileiro e a transformação dos seus meios de vida" iniciada em 1947, porém só publicada no ano de 1964. Entretanto, os livelihoods (meios de vida) passam a ser mais amplamente discutidos a partir de uma publicação do IDS (Institute of Development Studies), em 1992, de Gordon Conway e Robert Chambers, passando a ser considerada como uma das melhores abordagens explicativas das estratégias de sobrevivência das pessoas pobres, e um excelente foco de direção de políticas públicas voltadas para o desenvolvimento rural (SCHNEIDER, 2010b). Ao estudarem estes conceitos, suas diferenças e aproximações, Pereira, Souza e Schneider, concluíram que a obra de Candido não trata dos

\footnotetext{
${ }^{10}$ O Programa Territórios da Cidadania (PTC) é uma estratégia de desenvolvimento regional sustentável e garantia de direitos sociais voltado às regiões do país que mais precisam, com objetivo de levar o desenvolvimento econômico e universalizar os programas básicos de cidadania. Dentre os territórios rurais, no âmbito do Programa de Desenvolvimento Sustentável dos Territórios Rurais (Pronat) o primeiro critério a definir o território como participante do PTC foi o IDH (LEITE, WESZ JUNIOR, 2012).

${ }^{11} \mathrm{O}$ IDHM brasileiro inclui três componentes em seu cálculo: IDHM Longevidade, IDHM Educação e o IDHM Renda. O IDHM é um número que varia entre 0 e 1, quanto mais próximo de 1, maior o desenvolvimento humano de um município (PNUD, 2013).
} 
mesmos meios de vida propostos por Conway e Chambers, tratandose de outra proposta, aplicada noutros contextos, sob outras óticas, embora com finalidades próximas, o estudo do homem rural e como este se ajusta ao meio ao qual está inserido (PEREIRA, SOUZA, SCHNEIDER, 2010).

O trabalho de Gordon Conway e Robert Chambers intitulado como "Sustainnable rural livehoods: practical concepts for the 21 century" propôs que o tema "meios de vida" fosse tratado de forma conjunta com o de sustentabilidade. Inclusive foi sugerido que o termo fosse chamado de meios de vida sustentável, já que o ano de sua publicação era 1992, ano da Conferência da Organização das Nações Unidas sobre Meio Ambiente e Desenvolvimento, a ECO-92, ocorrida na cidade do Rio de Janeiro (PERONDI, 2007).

Conway e Chambers (1992), explicam os meios de vida, como: capacidades, ativos (estoques, recursos, direitos e acessos) e atividades requeridas para se obter um meio de vida. Os autores ainda propuseram que para um meio de vida ser sustentável deveria ser capaz de: a) suportar as crises mantendo elevadas as suas capacidades e ativos; b) prover um meio de vida sustentável para a próxima geração e c) contribuir em rede com benefícios para outros meios de vida em nível global, tanto no curto quanto no longo prazo (PERONDI, 2007).

Como ressalta Perondi (2007), para os mesmos autores, a sustentabilidade dos meios de vida poderia ser tanto numa perspectiva ambiental como social. $\mathrm{Na}$ perspectiva ambiental avaliando os impactos externos de um meio de vida sobre os outros meios de vida e na perspectiva social avaliando a capacidade interna de um meio de vida resistir à pressão externa como em uma crise, por exemplo.

Para o debate sobre os meios de vida sustentáveis, existem duas publicações que fundamentam tal discussão. Primeiramente 0 artigo escrito por Conway e Chambers (1992) que serviu para conceituar os meios de vida e estabelecer os vínculos com a sustentabilidade. E, por conseguinte, o trabalho de Scoones (1998) que formulou um diagrama de análise dos meios de vida sustentáveis apresentados na figura 1, a seguir. 


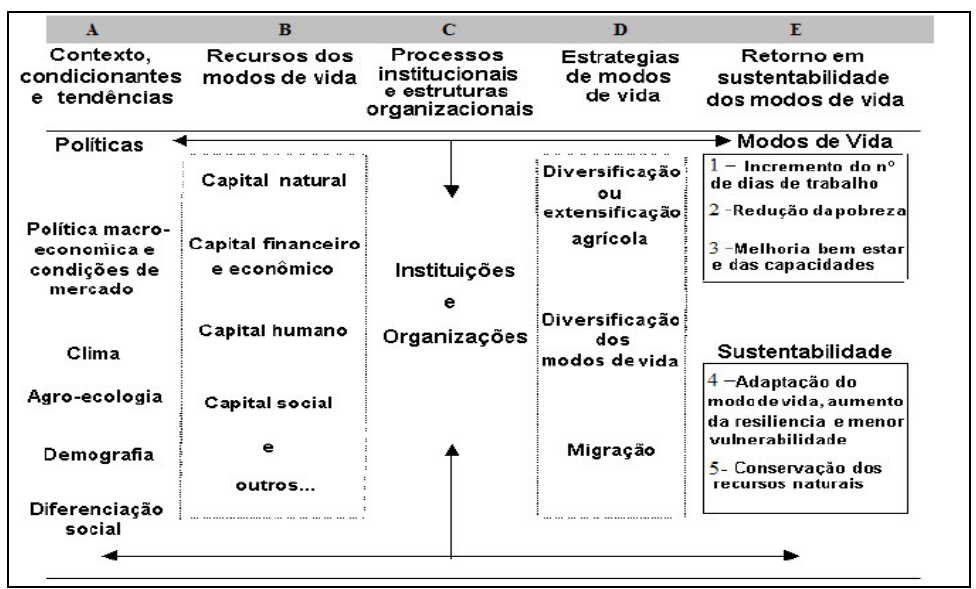

Figura 1 - Meios de vida rural sustentável: um diagrama de análise.

Fonte: Scoones (1998) apud Perondi (2007).

O diagrama da figura 1, segundo Perondi (2007), é um esquema interpretativo dos meios de vida das pessoas pobres que demonstra as interações que ocorrem entre os diferentes elementos do sistema. Na coluna $A$, verifica-se o contexto de vulnerabilidade em que as pessoas estão imersas. Na coluna B, estão os recursos dos meios de vida que as pessoas podem acessar. Na coluna $\mathrm{C}$, estão as instituições e organizações que regulam o acesso aos recursos dos meios de vida, formando possíveis conjuntos de acesso. Na coluna $D$, estão o cruzamento do contexto, dos diferentes recursos e das possibilidades de acesso que geram as estratégias de meios de vida das pessoas. Pode-se observar que no diagrama, as estratégias são agrupadas em três tipos alternativos e/ou concomitantes: intensificação/extensificação agrícola, diversificação e migração. E por último a coluna $E$, possibilita a observação dos resultados alcançados pelos meios de vida num retorno social: 1) maior empregabilidade, 2) redução da pobreza, 3) melhor bem-estar e retorno ambiental, 4) resiliência e 5) segurança dos recursos naturais.

Conforme Perondi (2007), esse diagrama passa a nortear toda a análise do programa de meios de vida sustentáveis do IDS, sendo citado e adaptado por vários autores e adotado pelo próprio DFID (British Department For International Developmen - órgão do governo britânico responsável pela promoção do desenvolvimento 
internacional) como o diagrama de orientação das suas políticas de anti-pobreza, como pode ser observado na figura 2 :

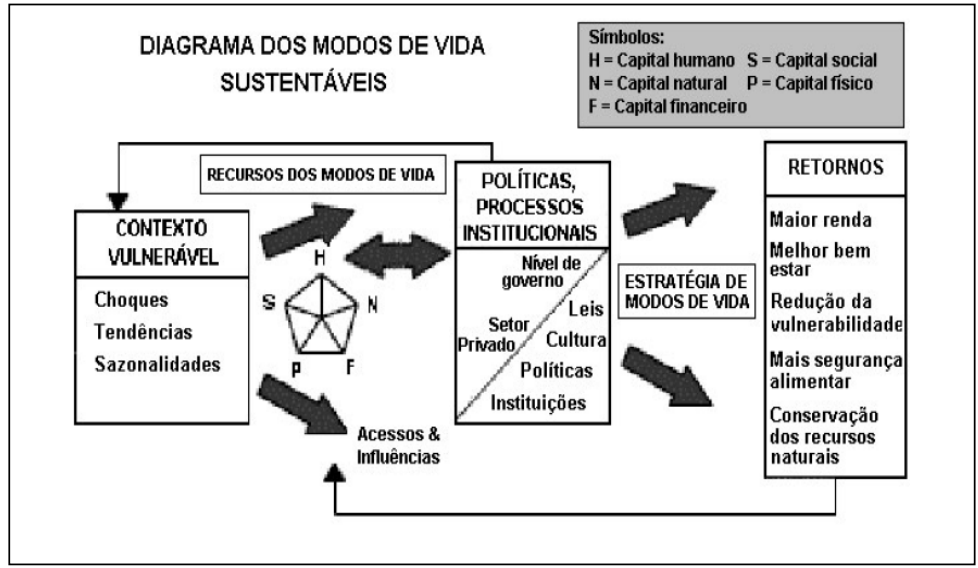

Figura 2 - Diagrama dos meios de vida sustentáveis do DFID

Fonte: Carney (1998) apud Perondi (2007).

Perondi (2007) destaca que os resultados do diagrama da figura 2, expressam os objetivos das políticas de melhoria dos meios de vida sustentáveis: a) maior renda, b) aumento do bem-estar, c) menor vulnerabilidade, d) maior segurança alimentar e) uso mais sustentável dos recursos naturais.

Outra síntese apresentada pelo mesmo autor com base no DFID informa que neste novo diagrama é consolidada a definição de que os recursos dos meios de vida são compostos por cinco capitais (natural, físico, humano, financeiro e social) simbolizados na forma de um pentágono que mais tarde Frank Ellis (2000) passa a adotar como o conjunto central e que define os meios de vida. Os cinco capitais abordados por Ellis (2000) referem-se ao capital natural que compreende a terra, a água e os recursos biológicos que são utilizados pelas pessoas para gerar seus meios de sobrevivência; ao capital físico que remete àquilo que foi criado pelo processo econômico de produção, como benfeitorias e máquinas, sujeitas ao desgaste pelo seu uso. Ao capital humano que é o trabalho doméstico disponível, influenciado pelas variáveis: educação, habilidades e saúde; o capital financeiro que compreende a liquidez que a família tem disponível para realizar suas estratégias, e por último, o capital social, que captura os vínculos do indivíduo e da 
família com a comunidade, em seu sentido social mais amplo (PERONDI, 2007).

Os vértices que compõe a figura geométrica do pentágono podem ser utilizados para demonstrar graficamente a variação do acesso de determinados grupos ou pessoas aos recursos dos capitais. O centro do pentágono, onde as linhas se encontram, representa acesso zero aos recursos, enquanto a parte externa representa o acesso máximo aos recursos. A partir desta análise, podem ser desenhadas formas diferentes de pentágonos para representar os meios de vida de diferentes comunidades ou grupos de indivíduos dentro de uma comunidade (PERONDI, 2007).

Apesar de diversos autores terem trabalhado com 0 conceito de meios de vida, foi Frank Ellis quem incorporou e enfatizou a "capacidade de diversificação" ao referido tema. Tal autor, define a capacidade de diversificação dos meios de vida como a "capacidade de criar a diversidade em processos sociais e econômicos, como também, o de pressionar e oportunizar às famílias para que diversifiquem o seu meio de vida, e seu entorno" (ELLIS, 2000 apud SCHNEIDER, 2010b).

Dessa forma, a diversificação não implica apenas na ampliação das possibilidades de obtenção de ingressos, especialmente rendas (agrícolas, não-agrícolas e outras), mas representa, sobretudo, uma situação em que a reprodução social, econômica e cultural é garantida por meio de uma combinação ou de um repertório variado de ações, iniciativas, escolhas, enfim, estratégias (SCHNEIDER, 2004). De forma geral o enfoque dessa teoria volta-se ao modo como os pobres rurais podem construir estratégias que lhes permitam enfrentar contextos de vulnerabilidade, entendidos como ambientes de sujeição à situação de risco e instabilidade social, econômica e ambiental (NIEDERLE; GRISA, 2008).

De acordo com Schneider (2010b), a abordagem dos meios de vida parte do pressuposto de que a diversificação dos recursos (ativos) disponíveis em uma propriedade rural resulta de um conjunto diversificado de atividades, que são tanto relacionados à agricultura como às atividades não agrícolas. $O$ resultado deste processo gera igualmente uma diversidade de fontes de rendimentos, que podem vir tanto de atividades produtivas como resultar da venda da força de trabalho dos agricultores, podendo ainda ser combinadas com 0 acesso a recursos financeiros externos através de órgãos governamentais, como transferências sociais e/ou políticas públicas. 
Nestes termos, a diversificação é um processo social e econômico, que implica em transformações de ordens e intensidades variadas, afetando diferentes dimensões e esferas.

Para Ploeg (2008) a análise da diversificação dos meios de vida implica na busca de fortalecimento da base de recursos disponíveis aos agricultores e da capacidade de luta constante por autonomia e liberdade frente a um contexto de hostilidade, privação e adversidade, consequência da modernização da agricultura. Com relação à diversificação dos meios de vida Frank Ellis assim a define: é o processo pelo qual as famílias rurais constroem um diversificado portfólio de atividades e de capacidades de apoio social para sobreviverem e melhorarem o seu padrão de vida (ELLIS, 1998). A contribuição de Ellis é interessante, pois vislumbra na capacidade das pessoas diversificarem os seus meios de vida, uma capacidade que cria a diversidade em processos sociais e econômicos e gera oportunidades às famílias para que diversifiquem suas rendas e a economia local (PERONDI; SCHNEIDER, 2012).

Por sua vez, tal como ressalta Schneider (2004), Ellis é cuidadoso e resistente quanto à atribuição de um sentido teórico à noção de desenvolvimento rural, preferindo defini-lo como um conjunto de ações e práticas que visam reduzir a pobreza em áreas rurais, visando estimular um processo de participação que apodera os habitantes rurais, tornando-os capazes de definir e controlar suas prioridades para a mudança. É neste ponto que a abordagem de Ellis, agora, pode ser complementada pela de Amartya Sen.

\subsection{Relação entre a abordagem das capacitações e a abordagem dos meios de vida}

A correlação da diversificação dos meios de vida com a abordagem de Amartya Sen segundo Schneider (2010b), está em afirmar que a ampliação das capacitações pode ocorrer por meio da diversificação. Ou seja, a interface está na ideia de que a ampliação das capacitações, no caso analisado por esta pesquisa, das famílias rurais produtoras de tabaco, pode ser realizada pela diversificação das formas de organização econômica e produtiva, social e ambiental. Portanto, pode-se dizer que quanto mais diversificada for a unidade produtiva, maiores serão as possibilidades de escolha e mais amplas as estratégias que poderão ser estabelecidas para o combate da vulnerabilidade.

Sendo assim, torna-se importante fortalecer os meios que as famílias dispõem para lidar com as adversidades que se apresentam no espaço em que vivem. De acordo com Ellis (2000) 152 
fortalecer os meios de vida (livehoods) permite criar mecanismos para diversificar as opções e estratégias de trabalho, renda, produção com o objetivo de amenizar ou diminuir a vulnerabilidade das famílias em relação às crises, choques, e instabilidades do mercado (SCHNEIDER, et al.,2012).

Com relação às famílias produtoras de tabaco e a ligação com a teoria de Sen da liberdade de escolha das pessoas em levar a vida que desejam, Rambo et al., (2013) exemplifica que, os meios e as capacidades de que dispõem estes produtores acabam compelindo-os e pressionando-os a se manterem fortemente dependentes e subordinados à cadeia produtiva de tabaco. Portanto, para este tipo de agricultores, o processo de diversificação da produção implica na construção de um portfólio que permita exercer o direito de escolha/opção. Estas escolhas/opções podem variar e implicar em um gradiente, variando entre aqueles que optam por permanecer dependentes e especializados na produção de tabaco, aqueles que apenas reduzem a produção sem abandonar o cultivo do tabaco e, por fim, aqueles que decidem deixar a produção e se dedicar a outros cultivos.

Frank Ellis ainda enfatiza sua preocupação em preservar e potencializar a capacidade de diversificação das pessoas ou de uma família rural, uma característica que proporciona a liberdade de escolher diferentes alternativas de renda num conjunto de possibilidades (PERONDI, SCHNEIDER, 2012). Desta forma, Ellis aproxima-se das discussões de Sen (2010), quando este sustenta que o desenvolvimento humano só é alcançado em plenitude na medida em que as famílias passam a ter a liberdade de escolher: Posto isso, pode-se dizer que só há desenvolvimento quando os benefícios do crescimento econômico conseguem ampliar as capacidades humanas - o conjunto das coisas que as pessoas podem ser ou fazer na vida (SCHNEIDER et al., 2012).

A seguir, apresenta-se a figura 3 que objetiva demonstrar esquematicamente a relação entre a abordagem das capacitações de Sen e a de diversificação dos meios de vida de Ellis. 


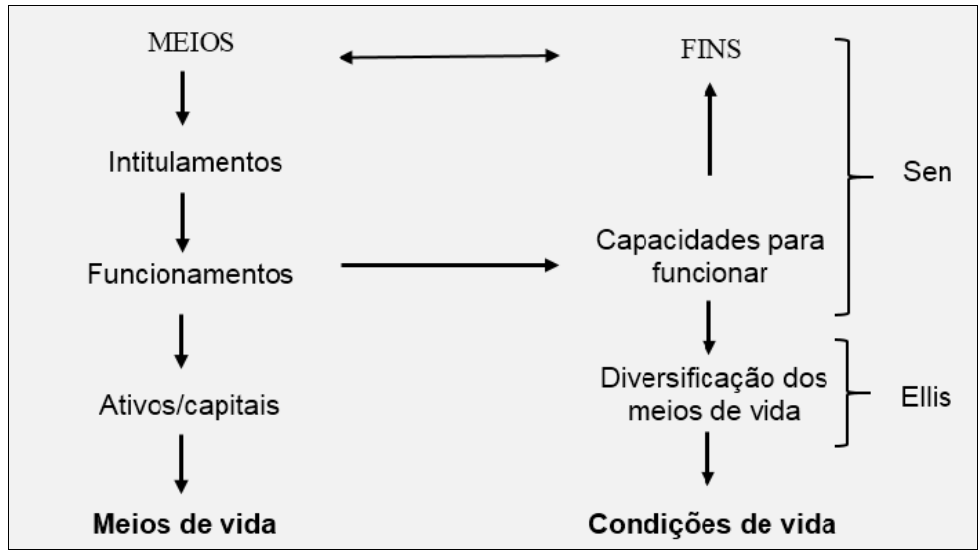

\section{Figura 3 - Relação entre a abordagem de Sen e Ellis}

Fonte: elaboração própria.

$\mathrm{Na}$ primeira coluna da figura 3 temos, os intitulamentos (SEN, 2012) que correspondem aos ativos ou capitais (assets) de ELLIS, (2000). Estes intitulamentos ou ativos caracterizariam os meios de vida junto aos funcionamentos, que dizem respeito ao conjunto de ativos, atividades, formas de acesso e uso que determinam o modo de viver de um indivíduo ou família (ELLIS, 2000). Na segunda coluna evidenciam-se as capacitações (SEN, 2012) que correspondem aos efeitos (ELLIS, 2000) ou às condições de vida. Relacionando intitulamentos, funcionamentos $e$ as capacitações será possível reconhecer quais meios de vida levam a quais condições de vida.

Por sua vez, como menciona Schneider et al., (2012), com base em Sen (1999, 2001), considera-se importante relacionar o que as famílias possuem com a percepção das mesmas acerca destes ativos. Portanto, o padrão, a qualidade ou as condições de vida não são medidas pela posse de um conjunto de bens, nem pela qualidade a eles inerente, mas sim pelas capacidades das famílias em utilizar tais bens para obter satisfação ou felicidade. Com base nisso, se por um lado não é suficiente apenas conhecer os bens ou ativos que as famílias possuem, por outro, também não é suficiente apenas conhecer as percepções destas famílias sobre suas condições de vida. 


\section{PROCEDIMENTOS METODOLÓGICOS PARA A APREENSÃO DOS MEIOS E CONDIÇÕES DE VIDA DOS AGRICULTORES FAMILIARES PRODUTORES DE TABACO}

A presente pesquisa é baseada na aplicação de dois instrumentos de coleta de dados a quarenta famílias produtoras de tabaco do município de Laranjeiras do Sul/PR. Estas famílias foram escolhidas de forma aleatória, buscando-se, no entanto, observar as diversas realidades encontradas no município. $O$ primeiro instrumento se refere a um questionário acerca dos meios de vida, que buscou levantar os capitais. O segundo buscou captar as condições de vida, levantando os efeitos dos capitais sobre as condições de vida das famílias, pautados na percepção dos entrevistados.

O primeiro instrumento buscou apreender os condicionantes/intitulamentos (Sen, 2012). Estes condicionantes/intitulamentos (fatores - ativos) caracterizariam os meios de vida, ou livelihoods, tal como apresenta Ellis (2000). O segundo instrumento remete a apreensão dos funcionamentos (Sen, 2012) ou efeitos (KAGEYAMA, 2008; ELLIS, 2000) referentes a cada meio de vida identificado pelo primeiro instrumento. Dessa forma, a pesquisa buscou observar quais meios de vida (instrumento 1) levam a quais condições de vida (instrumento 2) o que, enfim, remete ao que Sen (2010) denomina de meios e fins do desenvolvimento. Ambos os instrumentos foram do tipo fechado e de múltipla escolha. Apresentaram as possibilidades de respostas estruturadas em escalas de avaliação, (escala lickert) que variavam de valores baixos a valores altos, acerca dos capitais e dos seus efeitos.

Os instrumentos deram origem a índices gerais - dos meios de vida (IMV) e das condições de vida (ICV) - e a índices por capital e por efeito. Os capitais e efeitos foram analisados pelas seguintes dimensões: natural, humano, social, financeiro e físico. Os índices variavam, de 0 (zero) a 1 (um) sendo que, quanto mais próximo de 1 , melhor o índice. $\mathrm{O}$ quadro 1 procura evidenciar a composição dos capitais e efeitos que compõem a avaliação dos meios e condições de vida: 
Quadro 1 - Capitais, Efeitos e seus Componentes

\begin{tabular}{|c|c|}
\hline Capitais/efeitos & Componentes \\
\hline \multirow{4}{*}{ Natural } & Existência de vegetação nativa \\
\hline & Práticas de conservação do solo \\
\hline & Uso de lenha na secagem do tabaco \\
\hline & Manejo e armazenamento dos agrotóxicos e \\
\hline \multirow{4}{*}{ Humano } & Existência de problemas de saúde \\
\hline & Gastos em remédios \\
\hline & Producão de alimentos \\
\hline & Condição de educação e acesso a mesma \\
\hline \multirow{3}{*}{ Social } & $\begin{array}{l}\text { Participação em atividades comunitárias } \\
\text { Formas de acesso à informação }\end{array}$ \\
\hline & Troca de serviços entre amigos/vizinhos \\
\hline & $\begin{array}{l}\text { Associação da família à cooperativas, } \\
\text { sindicatos, associacões... }\end{array}$ \\
\hline \multirow{5}{*}{ Físico } & $\begin{array}{l}\text { Condições da moradia (casa de alvenaria, acesso à } \\
\text { energia elétrica, geladeira, televisor, telefone, } \\
\text { computador, internet, automóvel, água e banheiros } \\
\text { dentro de casa) }\end{array}$ \\
\hline & Acesso a máquinas e equipamentos \\
\hline & Distancia da propriedade da cidade \\
\hline & $\begin{array}{l}\text { Condiçoes das estradas } \\
\text { Existência de transporte público }\end{array}$ \\
\hline & Área produtiva da propriedade \\
\hline \multirow{5}{*}{ Financeiro } & Existência de fonte de renda além do tabaco \\
\hline & Acesso a canais de comercialização \\
\hline & Acesso às políticas para a agricultura familiar \\
\hline & Finalidade do acesso às políticas para a \\
\hline & $\begin{array}{l}\text { agricultura tamillar } \\
\text { Grau de endividamento }\end{array}$ \\
\hline
\end{tabular}

Fonte: Elaboração própria com base em Ellis (2000).

Vale ressaltar que para cada pergunta do instrumento 1 havia uma pergunta correspondente no instrumento 2. O IMV resultou da média simples de seus capitais e o ICV é resultado da média simples dos efeitos. Ambos, capitais e efeitos, tiveram o mesmo peso na composição da média geral de seus índices. $O$ índice correspondente a cada capital ou efeito também é resultado da média simples das respostas obtidas, tendo todas as perguntas 0 mesmo peso.

A compilação dos dados foi realizada a partir do software Excel, no qual foram digitadas as respostas dos questionários que 
deram origem a gráficos de radar, os chamados biogramas (SEPÚLVEDA, 2005). Para estabelecer a relação entre meios e condições de vida, foi definida uma tipologia acerca do grau de diversificação dos meios de vida.

Como aponta Schneider et al., (2012), a diversificação consiste num processo de construção de oportunidades, de incremento das capacidades dos agricultores para que possam optar e decidir. A diversificação remete, portanto, à questão da produção da autonomia dos produtores, que consiste na geração de possibilidades para que tenham a liberdade de opção de produzir aquilo que desejam e da forma que desejam. Assim, pode-se estabelecer que há graus de diversificação que variam entre os agricultores, que dependerá das opções que vierem a tomar, da disponibilidade de recursos a que tiverem acesso e da capacidade de utilizar estes recursos. Para definir o grau de diversificação dos agricultores produtores de tabaco é necessário estabelecer uma definição operacional e heuristicamente viável, mas que seja fiel a definição teórica acima exposta ${ }^{12}$.

Para tal, foi considerado o montante que o tabaco representa nas receitas da família e o tempo de trabalho dispensado pela família na produção do tabaco, tal como consta na figura 4 . Foram consideradas todas as receitas da família: agrícolas e não agrícolas, dentro e fora do estabelecimento. A partir destas duas variáveis os agricultores que produzem tabaco foram classificados em três categorias que variavam das famílias diversificadas (até $50 \%$ da receita e até $50 \%$ do tempo de trabalho dedicado ao tabaco) às especializadas (mais de $75 \%$ da receita ou do tempo de trabalho voltado ao tabaco), passando pelas pouco diversificadas (demais casos que não se enquadram nos anteriores).

\footnotetext{
${ }^{12}$ Embora se reconheça a amplitude qualitativa das abordagens de Sen e Ellis, neste estudo, optou-se por quantificar os graus de diversificação com base em duas variáveis, para operacionalizar as abordagens teóricas. Ademais, a necessidade inicial por tal metodologia que se deu por parte da Secretaria da Agricultura Familiar, demandava um instrumento de rápida e fácil aplicação, não sendo possível um estudo aprofundado e qualitativo.
} 


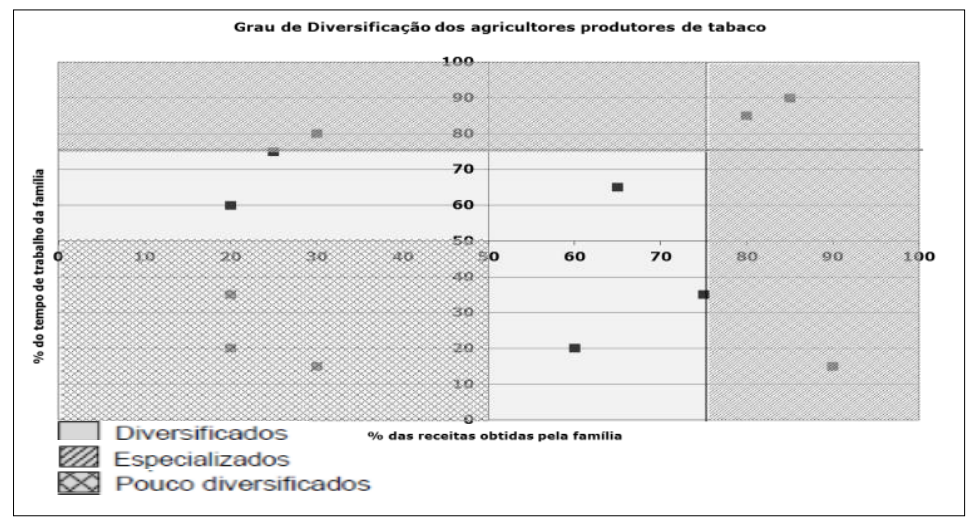

Figura 4 - Grau de diversificação das famílias produtoras de tabaco.

Fonte: Schneider et al., (2012).

A partir desta tipologia é possível observar as condições de vida das famílias diversificadas, pouco diversificadas e especializadas no município de Laranjeiras do Sul.

\subsection{Os meios e as condições de vida dos agricultores familiares produtores de tabaco no município de Laranjeiras do Sul/PR - Resultados e Discussões}

No município de Laranjeiras do Sul/PR, foram entrevistadas quarenta famílias (de um universo de 229 famílias) que produzem tabaco do tipo Burley, das quais $27,5 \%$ diversificadas, $35 \%$ especializadas e $37,5 \%$ pouco diversificadas, conforme critérios anteriormente apresentados. Este resultado denota equilíbrio entre as famílias que produzem tabaco no município quanto ao seu grau de diversificação. Por outro lado, comparando as famílias diversificadas e pouco diversificadas com as especializadas, verificase que o grau de diversificação é considerável, sendo que $65 \%$ das famílias apresentam algum grau de diversificação ${ }^{13}$.

\footnotetext{
${ }^{13}$ É importante enfatizar que no caso da pesquisa realizada no município de Arroio do Tigre (RS), apenas $13 \%$ das famílias entrevistadas apresentou meio de vida diversificado, $26 \%$ pouco diversificado e $61 \%$ especializado, o que demonstra que os agricultores familiares produtores de tabaco demonstram um considerável grau de diversificação e uma realidade distinta a apresentada no município gaúcho.
} 158 


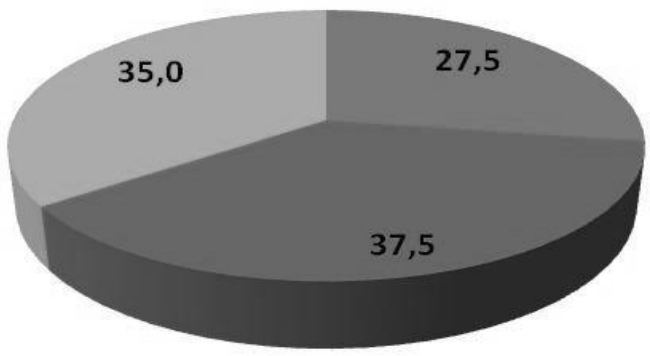

Diversificados $\quad$ Pouco diversificados Especializados

Figura 5 - Grau de diversificação das famílias entrevistadas em Laranjeiras do Sul

Fonte: Elaboração própria.

O universo pesquisado apresentou um Índice de Meios de Vida de 0,655 e um Índice de Condições de Vida de 0,738. Os respectivos biogramas podem ser observados abaixo:
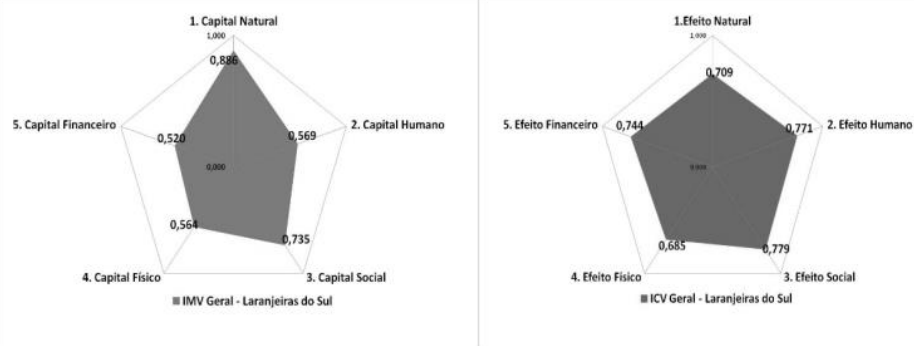

Figura 6 - Biogramas representativos do IMV e do ICV em Laranjeiras do Sul/PR

Fonte: Elaboração própria

Este resultado demonstra que as percepções dos entrevistados sobre suas condições de vida são melhores em relação a seus capitais. Fica evidente que a área do biograma representativo do ICV é maior e mais equilibrado em relação ao IMV. A não equivalência entre meios de vida e condições de vida pode ser uma informação importante na identificação dos aspectos que afetam 
mais diretamente as condições de vida destas famílias (SCHNEIDER et al., 2012). Esta situação, inicialmente, evidencia que os agricultores familiares possuem considerável capacidade de levar a vida que desejam (SEN, 2010; 2012), na medida em que conseguem transformar capitais escassos em efeitos positivos sobre suas condições de vida. Entretanto, ao se considerar questões específicas e relatos dos entrevistados, pode-se visualizar elementos que permitem observar situações de vulnerabilidade, como será destacado abaixo, com relação às dimensões financeira e física.

Considerando o grau de diversificação, as famílias diversificadas apresentaram melhor IMV $(0,660)$ seguida das poucos diversificadas $(0,654)$ e das especializadas $(0,646)$. Já quanto ao ICV, nota-se que os agricultores diversificados e os poucos diversificados apresentaram ICV iguais ficando em 0,742, mostrando-se melhores que os especializados, índice que ficou em 0,734 , como pode ser visualizado no gráfico abaixo. Considerando que os agricultores diversificados apresentaram melhor IMV e melhor ICV em relação às demais categorias comprova-se a hipótese inicialmente levantada, ou seja, as condições de vida dos agricultores familiares produtores de tabaco são influenciadas pela diversificação de seus meios de vida, o que, por sua vez, amplia sua liberdade em optar por diferentes estilos de vida.

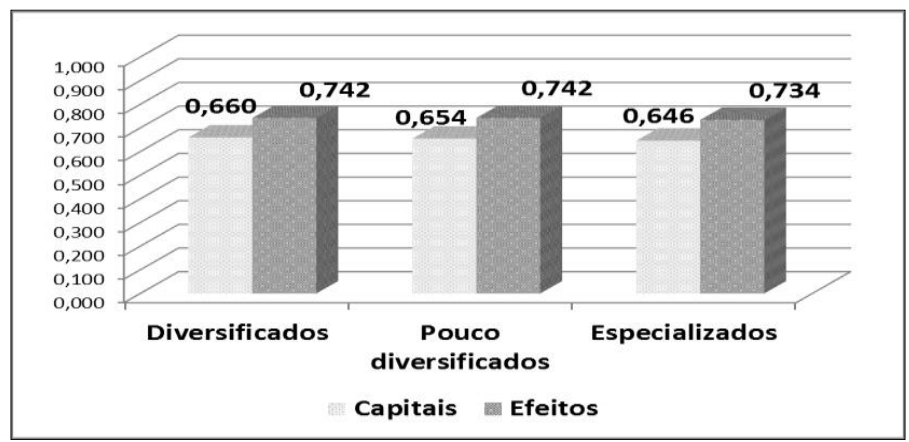

Figura 7 - Comparação entre IMV e ICV dos produtores de tabaco de Laranjeiras do Sul/PR

Fonte: Elaboração própria.

Nesse sentido, pode-se afirmar que os agricultores diversificados, ou seja, aqueles que obtêm até $50 \%$ da receita e dedicam até $50 \%$ do tempo de trabalho ao tabaco, mostram-se menos vulneráveis a esta cadeia produtiva, uma vez que possuem receitas mais diversificadas, mais tempo a ser dedicado a outras 160 
atividades (produtivas ou não) e assim, maior liberdade para escolher diferentes meios de vida. Isso é reforçado, ao se observar a figura 9 (a seguir), a qual aponta que a percepção dos efeitos dos capitais das famílias diversificadas é melhor em relação às demais categorias.

No que se refere aos índices gerais, é possível observar que o capital mais vulnerável é o financeiro $(0,520)$ e o mais elevado é representado pelo capital natural $(0,886)$. Quanto aos efeitos, o índice mais baixo remete ao físico $(0,685)$ e o mais elevado ao social $(0,779)$. Cabe destacar que, apesar do ICV mostrar-se maior em relação ao IMV, é nos capitais onde se encontra o índice mais elevado, conforme pode ser visualizado na figura 6 acima.

Já ao observar o biograma da figura 8, é possível verificar que o capital financeiro é a dimensão mais baixa entre as três categorias de agricultores familiares produtores de tabaco. Os especializados, com pior índice - 0,517 - são seguidos dos pouco diversificados $(0,529)$ e dos diversificados $(0,534)$ com melhor índice, o que novamente corrobora a hipótese acima exposta.

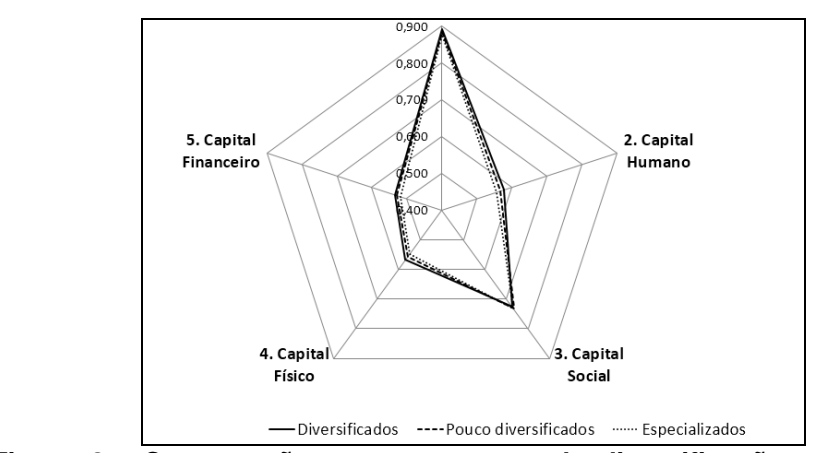

Figura 8 - Comparação quanto ao grau de diversificação e capitas Laranjeiras do Sul/PR

Fonte: Elaboração própria.

Por sua vez, o mesmo resultado não se repete no caso do ICV. O efeito financeiro não é o menor desta dimensão, como poderse-ia esperar inicialmente. Nesta situação, os agricultores pouco diversificados apresentam melhor índice $(0,750)$ seguido dos especializados $(0,749)$ e dos diversificados $(0,739)$. É importante atentar que a dimensão de menor índice quanto às condições de vida remete ao efeito físico, ou seja, a percepção dos entrevistados 
sobre as condições de moradia e infraestrutura na propriedade. Esta é a dimensão que possui uma relação mais direta com o capital financeiro. Neste caso, observa-se a seguinte configuração: os agricultores diversificados apresentam um índice de 0,688 no efeito físico; seguido dos pouco diversificados $(0,682)$ e especializados $(0,680)$.

Desta forma, pode-se inferir que a hipótese que afirma que a produção de tabaco contribui, sobretudo para ampliar o capital financeiro das famílias produtoras de tabaco, o que não necessariamente se reverte em melhores condições de vida se confirma em parte. As entrevistas apontaram que a dimensão financeira mostra-se a mais baixa entre os capitais (IMV). Sendo assim, a renda do tabaco não se reflete propriamente no capital financeiro. Quanto aos efeitos financeiros, estes mostram índices mais elevados em relação ao respectivo capital, sendo a terceira pior dimensão do ICV. Contudo, ao se observar as perguntas que compõem o efeito financeiro, em especial, a que se refere ao grau de satisfação com a renda gerada pelo tabaco, esta alcança o índice mais elevado, qual seja, 0,858. Isso demonstra que existe uma percepção de que a renda gerada pelo tabaco é significativa, porém, isto não se reflete nem no capital financeiro, nem no efeito físico, mais diretamente relacionado às dimensões financeiras e desta forma, não se reverte em melhores condições de vida.

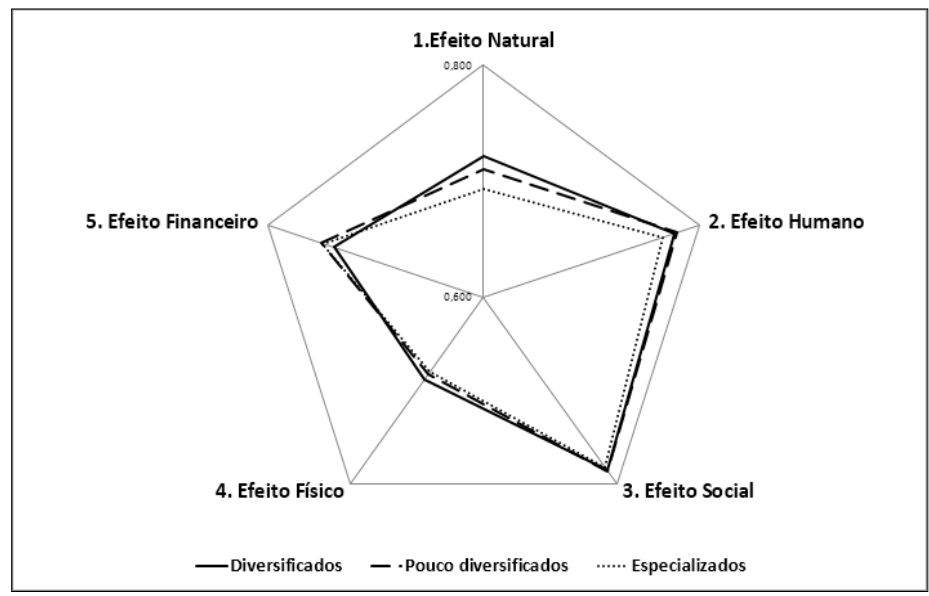

Figura 9 - Comparação quanto ao grau de diversificação e efeitos Laranjeiras do Sul/PR

Fonte: Elaboração própria.

162 
Ficou evidenciado ainda que, apesar das famílias diversificadas, em geral, apresentarem melhores índices nas dimensões, não há alterações quanto ao ranking dos maiores capitais e efeitos. Em ordem decrescente, os capitais vão do natural, passando pelo social, humano, físico chegando ao financeiro. Quanto aos efeitos, está o social, passando pelo humano, financeiro, natural chegando ao físico, também do maior para o menor índice. Os maiores e menores índices podem ser observados abaixo:

\begin{tabular}{|c|c|c|c|c|c|c|c|c|}
\hline $\begin{array}{r}\text { Dimensõ } \\
\text { es } \\
\text { Categori } \\
\text { as }\end{array}$ & $\begin{array}{l}\text { Meno } \\
r \\
\text { capita } \\
I \\
\end{array}$ & $\begin{array}{l}\text { Índi } \\
\text { ce }\end{array}$ & $\begin{array}{l}\text { Me } \\
\text { nor } \\
\text { efei } \\
\text { to }\end{array}$ & $\begin{array}{l}\text { Índi } \\
\text { ce }\end{array}$ & $\begin{array}{l}\text { Mai } \\
\text { or } \\
\text { capi } \\
\text { tal }\end{array}$ & $\begin{array}{l}\text { Índi } \\
\text { ce }\end{array}$ & $\begin{array}{l}\text { Mai } \\
\text { or } \\
\text { efei } \\
\text { to }\end{array}$ & $\begin{array}{l}\text { Índi } \\
\text { ce }\end{array}$ \\
\hline $\begin{array}{c}\text { Diversific } \\
\text { ados }\end{array}$ & $\begin{array}{l}\text { Finan } \\
\text { ceiro }\end{array}$ & 0,5 & $\begin{array}{l}\text { Físi } \\
\text { co }\end{array}$ & & $\begin{array}{l}\text { Nat } \\
\text { ural }\end{array}$ & 0,8 & $\begin{array}{l}\text { Soc } \\
\text { ial }\end{array}$ & $\begin{array}{l}0,7 \\
86 \\
\end{array}$ \\
\hline $\begin{array}{l}\text { Pouco } \\
\text { diversific } \\
\text { ados }\end{array}$ & & 29 & $\begin{array}{l}\text { Físi } \\
\text { co }\end{array}$ & $\begin{array}{l}0,6 \\
82\end{array}$ & $\begin{array}{l}\text { Nat } \\
\text { ural }\end{array}$ & & $\begin{array}{l}\text { Soc } \\
\text { ial }\end{array}$ & $\begin{array}{l}0,7 \\
86\end{array}$ \\
\hline $\begin{array}{c}\text { Especiali } \\
\text { zados }\end{array}$ & $\begin{array}{l}\text { Finan } \\
\text { ceiro }\end{array}$ & $\begin{array}{l}0,5 \\
17\end{array}$ & $\begin{array}{l}\text { Físi } \\
\text { co }\end{array}$ & $\begin{array}{l}0,6 \\
80\end{array}$ & $\begin{array}{l}\text { Nat } \\
\text { ural }\end{array}$ & $\begin{array}{l}0,8 \\
77\end{array}$ & $\begin{array}{l}\text { Soc } \\
\text { ial }\end{array}$ & $\begin{array}{l}0,7 \\
82 \\
\end{array}$ \\
\hline
\end{tabular}

Tabela 1 - Grau de diversificação e suas dimensões de capital e efeito. Fonte: Elaboração própria.

Importa destacar que entre os capitais, as famílias diversificadas apresentam índices menores em relação as demais categorias apenas na dimensão social, sendo de 0,726; seguida das pouco diversificadas $(0,733)$ e especializadas $(0,731)$. Quanto aos efeitos, na dimensão humana, os diversificados $(0,776)$ perdem para os pouco diversificados $(0,779)$ embora permaneçam com melhor índice que os especializados $(0,766)$. No efeito financeiro tem-se os pouco diversificados $(0,750)$, especializados $(0,749)$ e diversificados $(0,738)$ e no efeito social os diversificados e pouco diversificados demonstram mesmo índice $(0,786)$ seguidos dos especializados $(0,782)$

Por outro lado, vale a pena destacar que o único efeito menor que o capital se refere à dimensão natural. Isso parece ter relação com o tipo de tabaco cultivado, uma vez que o predominante no município de Laranjeiras do Sul não depende de lenha para a secagem, uma variável considerada nesta dimensão. Pesou negativamente no efeito, a questão dos agrotóxicos, sendo apontado que ao longo dos anos seu uso ou se manteve ou aumentou. A 
relação entre capitais e efeitos e as categorias de famílias de agricultores produtores de tabaco expostas até aqui podem ser visualizadas na figura 10 a seguir:

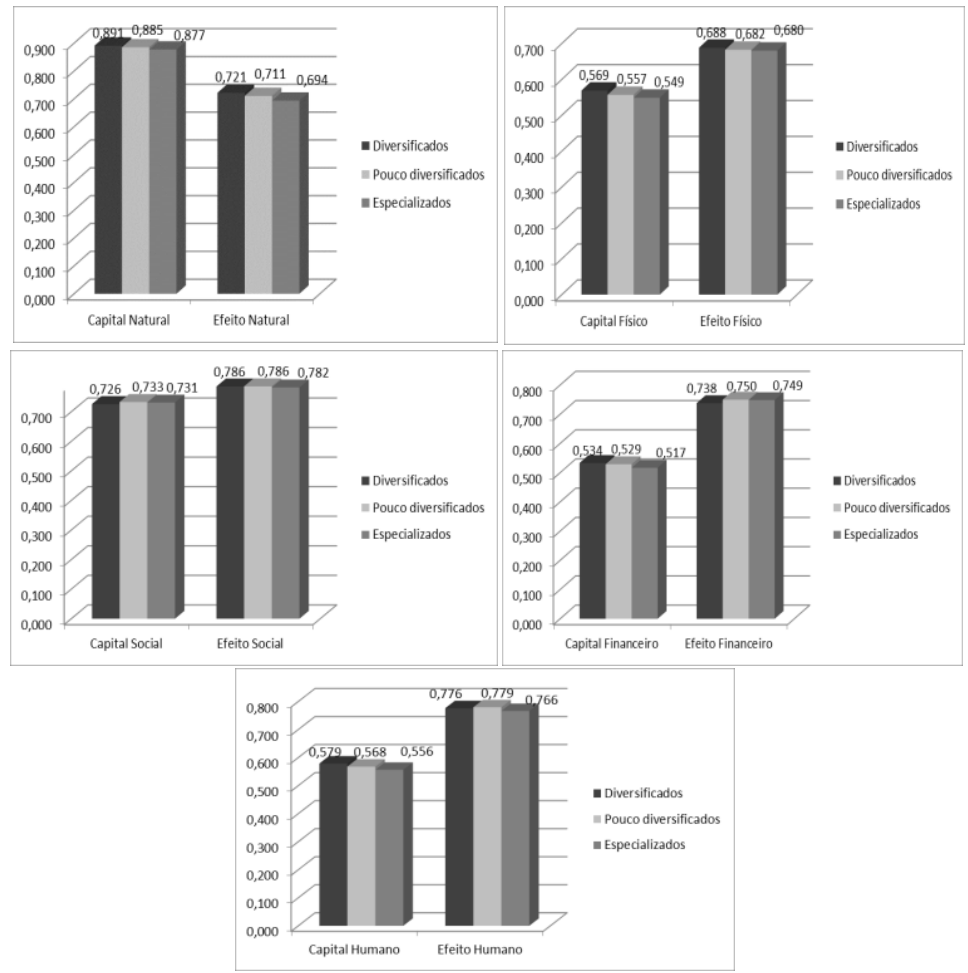

Figura 10 - Comparação entre capital e efeito quanto ao grau de diversificação dos produtores de tabaco - Laranjeiras do Sul/PR Fonte: Elaboração própria.

Observando que a percepção dos entrevistados é melhor em relação aos efeitos se comparada aos capitais (IMV de 0,655 e ICV de 0,738 ) poder-se-ia deduzir, a priori, que há menor propensão a políticas de diversificação entre os agricultores familiares produtores de tabaco do município de Laranjeiras do Sul, justamente pelo fato de demonstrarem considerável satisfação com os efeitos 
dos capitais que dispõem. Por sua vez, as relações acima apontadas quanto às dimensões financeiras e físicas demonstram que o gargalo dos meios e condições de vida destes agricultores está nestas dimensões, o que sugere que políticas de diversificação seriam mais apropriadas nestas dimensões.

Por outro lado, questões aplicadas, para além das que compuseram os instrumentos do IMV e do ICV, reforçam a realidade paradoxal: por um lado mostra-se uma atividade rentável e lucrativa e por outro gera uma situação de dependência e de vulnerabilidade, que fragilizam as famílias e geram situações de pobreza e risco, na produção de tabaco. Estas perguntas reforçam que os agricultores possuem liberdade limitada ao afirmarem que estão satisfeitos com a produção do tabaco, no entanto, não desejam que seus filhos continuem com esta atividade, muito embora demonstrem interesse que permaneçam na agricultura. Tais afirmações podem ser observadas na figura a seguir:

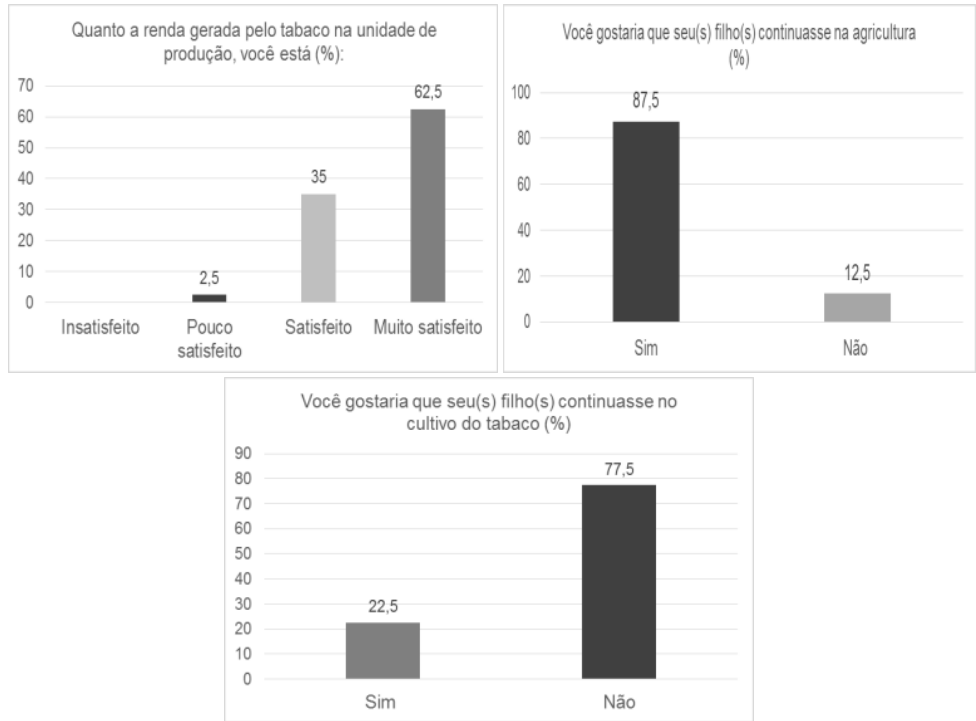

Figura 11 - Percepção dos entrevistados em relação ao tabaco e ao futuro a família na atividade - Laranjeiras do Sul/PR

Fonte: elaboração própria. 
De acordo com os gráficos acima, pode se fazer algumas considerações acerca da pesquisa com os produtores de tabaco de Laranjeiras do Sul/PR. Primeiramente, verifica-se que a produção de tabaco apresenta várias contradições entre os próprios agricultores. Quando questionados se estavam ou não satisfeitos com a renda gerada pelo tabaco, a grande maioria - $62,5 \%$ - respondeu que estava muito satisfeito com esta renda, 35\% respondeu que estava satisfeito e apenas $2,5 \%$ respondeu que estava pouco satisfeito. Por outro lado, quando questionados sobre continuidade de seus filhos na produção de tabaco, a grande maioria - $77,5 \%$ - respondeu que não gostaria que os mesmos continuassem a plantar tabaco. Estes resultados nos permitem inferir que existe sim, uma grande controvérsia no que tange a produção de tabaco na agricultura familiar e que a percepção da renda gerada por essa produção é um fator determinante para que os agricultores continuem a produzi-lo, porque se estes tivessem a liberdade e a capacidade de escolha, possivelmente escolheriam outra atividade para si e para sua família. Talvez a explicação mais plausível seja mesmo aquela que explicita que a falta de liberdade das pessoas condicionam as mesmas a realizar determinadas atividades e levaram este ou aquele meio de vida (SEN, 2010; 2012).

Os resultados da pesquisa em Laranjeiras do Sul também mostraram um equilíbrio quanto ao grau de diversificação dos produtores de tabaco. Com estes resultados pode-se fazer algumas reflexões acerca de como vivem estas famílias, ou seja, como se expressam seus meios e suas condições de vida, e também sobre algumas questões relacionadas as liberdades destas famílias em levar determinado tipo de vida.

Diante destes resultados, o que seria mais interessante para as famílias produtoras de tabaco? Diversificar ou especializar-se em um único cultivo? A resposta para essa questão parece passar pela ordem contextual e empírica, e a priori não é possível ter uma resposta considerada certa ou errada (NIEDERLE; GRISA, 2008). Para alguns agricultores, a especialização se mostra mais atraente e mais lucrativa, pois permite que estes utilizem da mão de obra e dos equipamentos que dispõe, não precisando utilizar de vários métodos de cultivos ou de equipamentos diversos que a diversificação produtiva poderia exigir. Entretanto, a especialização gera maiores riscos para as famílias a medida que estas ficam refém apenas de um ou de poucos produtos, podendo estes sofrerem com intemperes climáticas e oscilações de mercado, o que vai ao encontro do que afirma Ellis (2000). 
Por estes motivos, Niederle e Grisa (2008), corroboram dizendo que a diversificação torna-se uma alternativa consistente por garantir maior estabilidade econômica frente a um contexto crescentemente incerto. Como já apontado neste trabalho, diversificar as opções e estratégias permite reduzir a instabilidade do processo de reprodução ocasionada por possíveis falhas em uma das rendas ou pela variabilidade e sazonalidade das rendas durante o ano (ELLIS, 2000 citado por NIEDERLE; GRISA, 2008).

No caso dos produtores de tabaco, a diversificação produtiva permite uma maior capacidade para funcionar no meio rural ampliando as possibilidades econômicas sociais e ambientais e as escolhas que as famílias podem realizar para melhorarem o espaço onde vivem e levarem a vida que desejam. Desta forma, e como aponta Schneider (2010b), quanto mais diversificada for a unidade produtiva, maiores serão as possibilidades de escolha e mais amplas as estratégias que poderão ser estabelecidas para o combate da vulnerabilidade.

Embora não tenha sido foco desta pesquisa, considerações interessantes podem ser feitas ao se comparar o estudo realizado em Laranjeiras do Sul (PR) e Arroio do Tigre (RS). No caso do segundo município, apesar dos agricultores diversificados também apresentarem índices maiores em relação aos demais, de modo geral, os efeitos mostraram-se piores em relação aos meios, situação contrária a visualizada em Laranjeiras do Sul. Ou seja, o ICV foi menor que o IMV.

Considera-se que uma explicação pode residir no fato do tipo de tabaco predominante nos dois municípios. Em Laranjeiras do Sul predomina o tipo Burley, enquanto em Arroio do Tigre, o tipo Virgínea. Este demanda mais mão de obra e tempo de trabalho além do uso de lenha para a secagem do tabaco em estufas. Isto explica também o fato de haver maior diversificação em Laranjeiras do Sul as famílias possuem mais tempo para se dedicar a outras atividades produtivas, sendo que a maioria concilia o cultivo do tabaco e a produção leiteira - se comparada ao outro município.

Outro diferencial observado nas duas pesquisas remete ao tempo em que o tabaco é cultivado nas duas regiões. Enquanto no RS a produção já se dá há várias gerações, no caso de Laranjeiras do Sul este cultivo inicia na década de 1980, sendo que, na maioria dos casos, é a primeira geração que está produzindo o tabaco. Isso interfere diretamente na questão dos agrotóxicos. Como o tempo de produção de tabaco é maior no RS, os agricultores percebem que a 
quantidade de agrotóxicos diminuiu ao longo dos anos, diferente do percebido pelos agricultores de Laranjeiras do Sul/PR.

\section{CONSIDERAÇÕES FINAIS}

O presente artigo procurou apresentar, por meio do uso de dois instrumentos de pesquisa, os meios e as condições de vida dos agricultores familiares produtores de tabaco do município paranaense de Laranjeiras do Sul. Considera-se que esta proposta teórico-metodológica apresenta avanços uma vez que propõe considerar tanto os meios quanto os fins de desenvolvimento, ou seja, não levanta apenas o que as pessoas ou famílias dispõem (os capitais), mas também, o que as famílias conseguem fazer/realizar com o que possuem (os efeitos).

Neste sentido, pode se recorrer às contribuições de Amartya Sen, que apontam a ideia de desenvolvimento como liberdade, destacando que há uma confusão entre meios e fins do desenvolvimento. Normalmente os meios são considerados fins, ou seja, para Sen (2010) a utilidade da riqueza está nas coisas que ela nos permite fazer - as liberdades substantivas que ela nos ajuda a obter e não nela mesma". Nesta perspectiva o autor desenvolve seus estudos com base nos conceitos de entitlements (intitulamentos) e functionings (funcionamentos). Os intitulamentos se referem ao que as pessoas têm ou possuem para viver, já os funcionamentos podem ser entendidos como as coisas que a pessoa tem razão de ser ou fazer (SEN, 2010). Apesar de inicialmente os biogramas apontarem para os melhores índices nos efeitos do que nos capitais, o que indicaria, a priori, certa capacidade para funcionar dos agricultores, ao analisar cada dimensão e suas relações, observa-se limitações como anteriormente exposto. Ademais, o fato dos agricultores almejarem que os filhos desenvolvam outras atividades e não a produção de tabaco corrobora esta inferência.

Ademais, no caso dos agricultores familiares produtores de tabaco de Laranjeiras do Sul, observou-se que as dimensões financeira (capital) e física (efeito) são as mais vulneráveis e limitam os meios e as condições de vida daquelas famílias. Portanto, ações e políticas públicas de diversificação com foco tornam-se pertinentes neste recorte espacial.

Por outro lado, buscou-se apontar também a importância da diversificação dos meios de vida, sobretudo para as famílias produtoras de tabaco, as quais, em geral e, sobretudo em determinadas regiões do Brasil, mostram elevados graus de especialização e dependência desta cadeia produtiva. 
Como os resultados em Laranjeiras do Sul apontaram melhores capitais e efeitos (melhores meios e fins) para os agricultores diversificados, pode-se trazer a esta discussão, as contribuições de Nierdele e Grisa (2008). Os autores afirmam que a diversificação torna-se uma alternativa consistente por garantir maior estabilidade econômica frente a um contexto crescentemente incerto. Como já apontado neste trabalho, diversificar as opções e estratégias permite reduzir a instabilidade do processo de reprodução ocasionada por possíveis falhas em uma das rendas ou pela variabilidade e sazonalidade das rendas durante 0 ano.

No caso dos produtores de tabaco, a diversificação dos meios de vida assume maior importância frente a CQCT. Ao incentivar a diminuição do consumo, isto poderá acarretar diminuição da produção, e assim, situações de vulnerabilidade, sobretudo aos agricultores especializados. A diversificação produtiva permite uma maior capacidade para funcionar no meio rural ampliando as possibilidades econômicas, sociais e ambientais e as escolhas que as famílias podem realizar para melhorarem o espaço onde vivem e levarem a vida que desejam. Desta forma, e como aponta Schneider (2010b) quanto mais diversificada for a unidade produtiva, maiores serão as possibilidades de escolha e mais amplas as estratégias que poderão ser estabelecidas para o combate da vulnerabilidade.

Por outro lado, quanto a proposta metodológica em si, podese afirmar que, a mesma mostra-se mais robusta na medida em que permite comparações, seja entre diferentes regiões ou diferentes momentos no tempo. Embora não tenha sido o foco deste artigo, um comparativo entre os resultados de Laranjeiras do Sul e Arroio do Tigre $^{14}$ levantam questões interessantes a serem analisadas e interpretadas. Observou-se, por exemplo, que o tipo de tabaco produzido mostrou relação com o grau de diversificação das famílias, com os índices referentes à saúde das famílias, e mesmo com os índices gerais do IMV e ICV.

Embora não seja possível aprofundar tais análises neste artigo, considera-se importante ressaltar que esta proposta teóricametodológica tem sua fortaleza na possibilidade de comparar pontos no espaço e no tempo. Além do mais, pode-se afirmar que esta é uma metodologia exploratória, ou seja, o IMV e ICV de determinado ponto no tempo e no espaço representa os meios e as condições de vida das famílias daquele recorte têmporo-espacial, podendo ser

\footnotetext{
${ }^{14}$ Sobre a pesquisa de Arroio do Tigre, ver Rambo et. al., (2013).
} 
compreendida como uma "fotografia" daquele recorte. De posse desta "fotografia", é possível realizar novas pesquisas, de forma mais aprofundada, para investigar o que levou à configuração da mesma.

Por fim, é importante mencionar que ainda há desafios a serem superados pela proposta teórico-metodológica, como por exemplo, a tendência às medias das respostas, sobretudo quando baseadas na percepção dos entrevistados bem como questões relativas às variáveis que definem o grau de diversificação das famílias.

\section{REFERÊNCIAS BIBLIOGRÁFICAS}

AFUBRA, Associação dos Fumicultores do Brasil. Santa Cruz do Sul, RS Fumicultura Sul-Brasileira. Disponível em: <http://www.afubra.com.br/index.php/conteudo/show/id/83> Acesso em: 17 jan. 2013.

\section{\begin{tabular}{cccc}
\multicolumn{2}{c}{ Fumicultura Sul-Brasileira e os minifúndios: distribuição } \\
fundiária & 2011/12.
\end{tabular} <http://www.afubra.com.br/index.php/conteudo/show/id/80> Acesso em: 03 ago. 2013.}

BRASIL. Ministério da Saúde. Instituto Nacional de Câncer. Convenção-Quadro para o Controle do Tabaco. Rio de Janeiro: INCA, $2011 . \quad$ Disponível em: <http://www1.inca.gov.br/inca/Arquivos/convencao_quadro_texto_ofi cial.PDF> Acesso em: 31 jul. 2013.

CONICQ - Comissão Nacional para Implementação da Convenção Quadro para Controle do Tabaco. A convenção quadro para controle do tabaco (cop5) e Produção de fumo: Análise de situação. Setembro de 2012.

DESER, Departamento de Estudos Sócio-Econômicos Rurais. Tabaco: da produção ao consumo. Uma cadeia da dependência. Curitiba: 2010.

ELLIS, Frank. Rural livelihoods and diversity in developing countries. Oxford: Oxford University, 2000.

ELLIS, Frank. Household Strategies and Rural Livelihood Diversication. The jounal of Development Studies, Vol. 35, № 1. October 1998, p.1-38. Published by Frank Cass, London.

FCTC - Convenio Marco de la OMS para el Control del Tabaco, 2003. Idioma espanhol. Disponível em: 
<http://whqlibdoc.who.int/publications/2003/9243591010.pdf> Acesso em: 15 jun. 2013.

GIL, Antonio Carlos, Métodos e técnicas de pesquisa social / Antonio Carlos Gil. 6. ed. - 3. Reimpr. - São Paulo: Atlas, 2010.

INCA - Instituto Nacional de Câncer/ Ministério da Saúde. A interferência da Indústria do Tabaco: Apresentações e orientações técnicas. Revisão: Rita Rangel de S. Machado. (2012). Disponível em:

<http://www.progepe.uff.br/sites/default/files/servicos/documentos/20 11_04_27_manual_31maio_rev_final.pdf> Acesso em: 17 maio 2013.

LEITE, Sergio Pereira.; WESZ JUNIOR, Valdemar João. Um estudo sobre o financiamento da política de desenvolvimento territorial no meio rural brasileiro. Rev. Econ. Sociol. Rural [online]. v.50, n.4, 2012, p. 645-666.

NIEDERLE Paulo André. GRISA Catia. Diversificação dos meios de vida e acesso a atores e ativos: uma abordagem sobre a dinâmica de desenvolvimento local da agricultura familiar. Cuadernos Des. Rural, Bogotá (Colombia), 5 (61): 41-69, julio-diciembre de 2008.

PEREIRA, Márcio de Araújo; SOUZA, Marcelino de; SCHNEIDER, Sérgio. Meios de vida e livelihoods: aproximações e diferenças conceituais. Revista IDEAS - Interfaces em Desenvolvimento, Agricultura e sociedade, Rio de Janeiro - RJ, v.4, n.1, p. 41-62, jan./jul. 2010.

PERONDI, Miguel Ângelo. Diversificação dos Meios de Vida e Mercantilização da Agricultura Familiar. Universidade Federal do Rio Grande do Sul. Tese de Doutorado apresentada ao Programa de Pós-Graduação em Desenvolvimento Rural - UFRGS. Porto Alegre, 2007.

PERONDI, Miguel Angelo. SCHNEIDER, Sérgio. Bases teóricas da abordagem de diversificação dos meios de vida. REDES - Rev. Des. Regional, Santa Cruz do Sul, v. 17, n. 2, p. 117-135, mai./ago. 2012.

PNUD, Programa das Nações Unidas para o Desenvolvimento. Atlas Brasil 2013: Rankings e recortes principais para avaliação do IDHM. 
<http://www.pnud.org.br/Noticia.aspx?id=3749 $\geq$ Acesso em: 31 jul. 2013.

PLOEG, Jan Douwe van der. Camponeses e impérios alimentares: lutas por autonomia na era da globalização / Jan Douwe van der Ploeg; tradução Rita Pereira. - Porto Alegre: Editora da UFRGS, 2008.

RAMBO, Anelise Graciele.; FREITAS, Tanise Dias.; RUDNICK, Carlise Schneider.; SCHNEIDER, Sérgio. Analisando a diversificação dos meios de vida de agricultores familiares produtores de tabaco: um estudo de caso no município de Arroio do Tigre/RS. Sociedade Brasileira de Economia, Administração e Sociologia Rural - SOBER, Belém - PA, 2013.

SANTOS, Larissa Martins Neiva. Pobreza como privação de liberdade: Um estudo de caso na favela do Vidigal no rio de Janeiro. Universidade Federal Fluminense - Niterói, Abril de 2007.

SCHNEIDER, Sergio. A pluriatividade na Agricultura Familiar. $2^{\mathrm{a}}$ ed. Porto Alegre: Editora da UFRGS, 2009.

Referências para a Elaboração de uma Matriz (template) de Análise da Diversificação da Produção em Áreas Cultivadas com Tabaco no Brasil. Porto Alegre, 2010a. (Relatório).

Diversificação como estratégia de desenvolvimento rural: referências teóricas para construção de alternativas economicamente sustentáveis de diversificação da produção e renda em áreas de cultivo de tabaco no Brasil - subsídios à implementação dos Artigos 17 e 18 da Convenção Quadro para Controle do Tabaco. Porto Alegre, 2010b. (Relatório).

A abordagem territorial do desenvolvimento rural e suas articulações externas. Sociologias, Porto Alegre, ano 6, no11. p. 88125. Jan./jun. 2004.

SCHNEIDER, Sérgio.; WAQUIL, Paulo.; XAVIER, Leonardo.; CONTERATO, Marcelo.; PERONDI, Miguel.; RAMBO, Anelise G.; RUDNICK, Carlise Schneider.; FREITAS, Tanise Dias.; ÁVILA, Kayton Fernandes de. Diretrizes metodológicas para análise da diversificação dos meios de vida dos produtores de tabaco: referências para identificar estratégias alternativas a partir de resultados preliminares baseados em um estudo de caso no Brasil. Porto Alegre, janeiro/2012. 
SEPÚLVEDA, Sergio. Desenvolvimento microrregional sustentável: métodos para planejamento local. Brasília: IICA, 2005.

SEN, Amartya Kumar. Desenvolvimento como liberdade/Amartya Sen; tradução Laura Teixeira Motta; revisão técnica Ricardo Dominelli Mendes. - São Paulo: Companhia das Letras, 2010.

Desigualdade reexaminada /Amartya Sen; tradução e apresentação de Ricardo Doninelli Mendes. - 3 $3^{\text {a }}$ ed. - Rio de Janeiro: Record, 2012.

SIT, Sistema de Informações Territoriais. Territórios Cidadanias: Território Cantuquiriguaçu - PR, 2013. Disponível em: $<$ http://sit.mda.gov.br/mapa.php?opcaomapa=TC\&modo=0> Acesso em: 02 jul. 2013.

SOUZA, Raquel Pereira. Convenção - Quadro para Controle do Tabaco: Reflexões sobre o futuro da fumicultura brasileira. 47ำ Congresso da Sociedade Brasileira de Economia, Administração e Sociologia Rural - SOBER. Porto Alegre, 26 a 30 de julho de 2009.

ZOTTI, Cleimary Fatima. Meios de vida alternativos a cultura do tabaco nos municípios de Capanema e Planalto - PR / Cleimary Fatima Zotti. - Porto Alegre, 2010. $128 \mathrm{f}$. 